Title: A gut sensor for sugar preference

Authors: Kelly L. Buchanan ${ }^{1,2}$, Laura E. Rupprecht ${ }^{1,3}$, Atharva Sahasrabudhe ${ }^{5,6,7}$, M. Maya Kaelberer $^{1,3}$, Marguerita Klein ${ }^{1,3}$, Jorge Villalobos ${ }^{1,3}$, Winston W. Liu ${ }^{1,3}$, Annabelle Yang ${ }^{1,4}$, Justin Gelman $^{1,4}$, Seongjun Park ${ }^{5,7,8}$, Polina Anikeeva ${ }^{5,7,9}$, and Diego V. Bohórquez ${ }^{1,3,10,11 * \dagger}$

\title{
Affiliations:
}

${ }^{1}$ Laboratory of Gut Brain Neurobiology, Duke University, Durham, NC

${ }^{2}$ Duke University School of Medicine

${ }^{3}$ Department of Medicine, Duke University, Durham, NC.

${ }^{4}$ Trinity College of Arts \& Sciences, Duke University, Durham, NC.

${ }^{5}$ Research Laboratory of Electronics, Massachusetts Institute of Technology, Cambridge, MA, USA.

${ }^{6}$ Department of Chemistry, Massachusetts Institute of Technology, Cambridge, MA, USA. ${ }^{7}$ Departments of Electrical Engineering and Computer Science, Massachusetts Institute of Technology, Cambridge, MA, USA.

${ }^{8}$ Department of Bio and Brain Engineering, Korea Advanced Institute of Science and Technology (KAIST), Daejeon 34141, Republic of Korea

${ }^{9} \mathrm{McGovern}$ Institute for Brain Research, Massachusetts Institute of Technology, Cambridge, MA, USA.

${ }^{10}$ Department of Neurobiology, Duke University, Durham, NC.

${ }^{11}$ Duke Institute for Brain Sciences, Duke University, Durham, NC.

*Correspondence to: diego.bohorquez@duke.edu

†Current address: MSRB-I, room 221A, 203 Research Drive, Durham, NC. 


\section{Summary Paragraph/Abstract:}

Animals innately prefer caloric sugars over non-caloric sweeteners. Such preference depends on the sugar entering the intestine..$^{1-4}$ Although the brain is aware of the stimulus within seconds, ${ }^{5-8}$ how the gut discerns the caloric sugar to guide choice is unknown. Recently, we discovered an intestinal transducer, known as the neuropod cell. ${ }^{9,10}$ This cell synapses with the vagus to inform the brain about glucose in the gut in milliseconds. ${ }^{10}$ Here, we demonstrate that neuropod cells distinguish a caloric sugar from a non-caloric sweetener using the electrogenic sodium glucose co-transporter 1 (SGLT1) or sweet taste receptors. Activation of neuropod cells by non-caloric sucralose leads to ATP release, whereas the entry of caloric sucrose via SGLT1 stimulates glutamate release. To interrogate the contribution of the neuropod cell to sugar preference, we developed a method to record animal preferences in real time while using optogenetics to silence or excite neuropod cells. We discovered that silencing these cells, or blocking their glutamatergic signaling, renders the animals unable to recognize the caloric sugar. And, exciting neuropod cells leads the animal to consume the non-caloric sweetener as if it were caloric. By transducing the precise identity of the stimuli entering the gut, neuropod cells guide an animal's internal preference toward the caloric sugar. 


\section{Main Text}

The cephalic senses guide our decision to eat. But what happens next, inside the gut, is essential for our eating preferences.

As early as 1952, it was known that animals prefer the side of a T-maze if rewarded by nutrients delivered directly into the stomach. ${ }^{1}$ Although the responses depend on the nutrient's caloric value, ${ }^{7,8,11}$ how this value is signaled by the gut epithelium to drive preference is unknown. Of all macronutrients, sugars and available analogs have the most defined sensory properties. For instance, sucrose - a compound sugar made of D-glucose and fructose- contains both taste and calorie, whereas non-caloric sweeteners, like sucralose, carry only taste. Animals have an innate preference for sucrose over non-caloric sweeteners, even in the absence of taste. ${ }^{3,12-14}$ Such preference depends on the sugar entering the intestine. ${ }^{2,3,15,16}$ But slow acting intestinal hormones cannot account for the effect, ${ }^{17}$ because the brain perceives stimuli from nutrients entering the small intestine within seconds. ${ }^{6,8,10}$ Thus, a fast intestinal sensor must exist to steer the animal towards the caloric sugar.

A gut sense for sweets. Intestinal signals arising from the lumen are relayed to the brain via the vagus nerve. ${ }^{6,10,11}$ The vagus responds within seconds to an intraluminal stimulus of sucrose, ${ }^{6,10,18}$ but the response to other sugars, including non-caloric sweeteners, is unclear. We therefore tested vagal firing responses to a panel of sugars: sucrose, D-glucose, fructose, galactose, maltodextrin, alpha-methylglucopyranoside ( $\alpha$-mgp), saccharin, acesulfame-K, and sucralose. All stimuli were perfused at physiological concentrations ${ }^{10}$ through the proximal duodenum, bypassing gustatory or gastric activation, while nerve responses were recorded using two electrodes placed at the cervical vagus (Fig. 1a). Almost all sugars elicited a significant increase in vagal firing rate within seconds ( $\mathrm{p}<0.001, \mathrm{n} \geq 5$; Fig. 1b, Extended Data Fig. 1a-b). But fructose did not (Extended Data Fig. 1c-d). Unlike D-glucose, it diffuses passively through the epithelium and does not have a clear reinforcing effect. ${ }^{19}$ All responses were confined to the small intestine, the primary site for sugar absorption ${ }^{20}$, which correlates with post-ingestive rewarding effects ${ }^{4}$ (Extended Data Fig. 2a-c).

Intestinal epithelial cells absorb glucose through active transport mediated by the sodium glucose co-transporter SGLT1. This electrogenic channel uses a sodium gradient to transport D-glucose into the cell. Thus, SGLT1 acts as a gate for D-glucose. ${ }^{21,22}$ Intestinal epithelial cells also express sweet taste receptors, specifically T1R2 and T1R3. ${ }^{23}$ We found that the vagal response to sucralose $[15 \mathrm{mM}]$ was abolished when these taste receptors were inhibited with gurmarin $[7 \mu \mathrm{M}]^{24}$ (Fig. 1c-e), but the response to sucrose $[300 \mathrm{mM}]$ or $\alpha-\mathrm{mgp}[150 \mathrm{mM}]$ remained intact (Fig. 1c-e). $\alpha$-mgp is a synthetic sugar that once inside the cell is not metabolized but, like Dglucose, $\alpha$-mgp enters the cell through SGLT1 (Extended Data Fig. 2d). ${ }^{21}$ As such, inhibiting SGLT1 with phloridzin $[3 \mathrm{mM}]^{25}$ abolished the response to both $\alpha$-mgp and sucrose (Fig. 1c-e). Phloridzin did not affect the vagal response to the luminal sucralose stimulus (Fig. 1c-e). The sweetness and caloric value of sugars are therefore represented in the vagus by two distinct signals emanating from the intestinal epithelium.

The sensor. Within the epithelium of the intestine, there is sensory transducer. This is the neuropod cell - an electrically excitable cell that synapses with nerves. ${ }^{5,10,26,27}$ Previously, we 


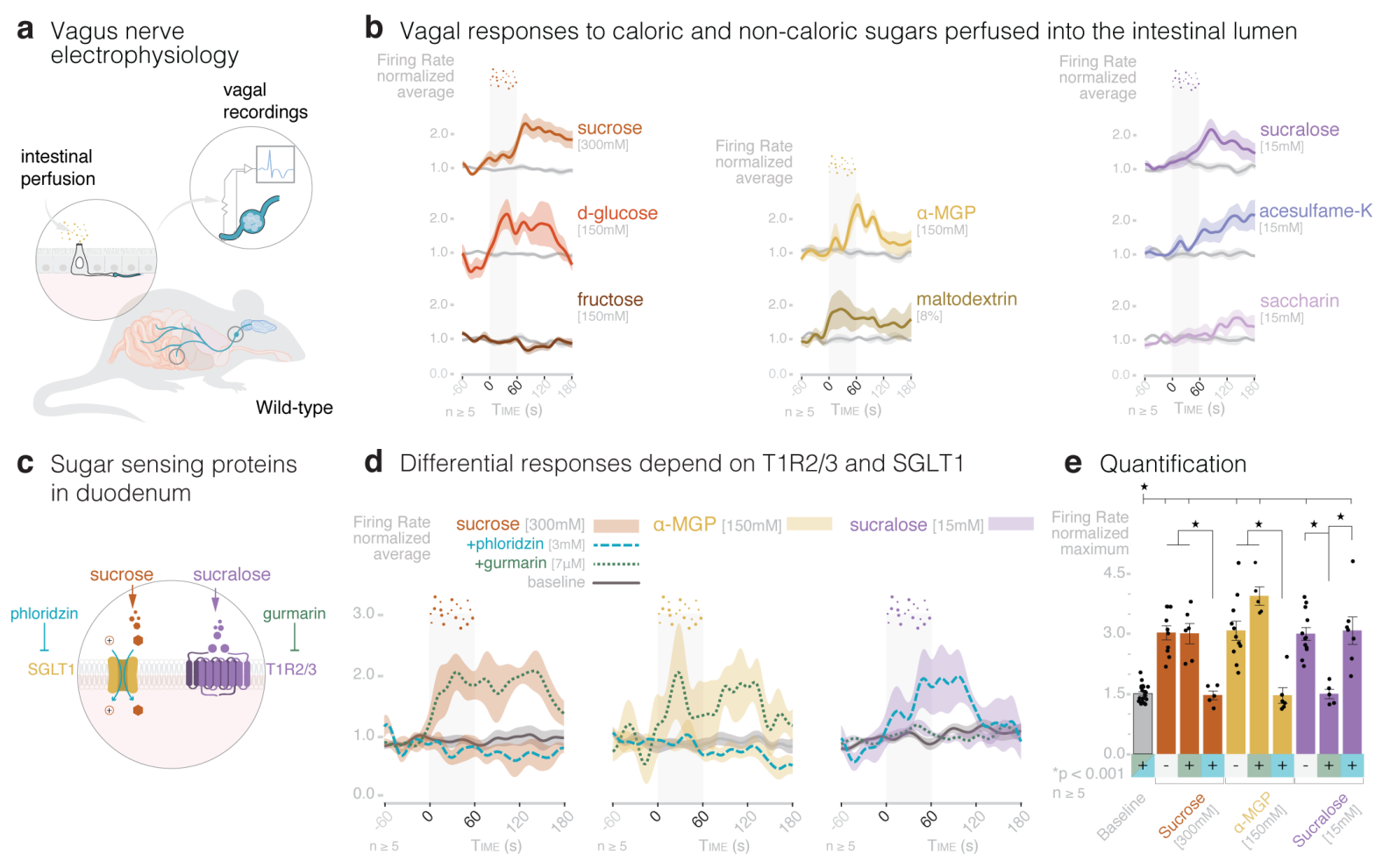

Fig. 1 Intraluminal sugars are represented in the vagus via the activation of sweet taste receptors (T1R2/3) or sodium-glucose co-transporter 1 (SGLT1). a, Model: sugars are perfused into the duodenal lumen while nerve activity is recorded from the cervical vagus of anesthetized wild-type mice. $\mathbf{b}$, The vagus responds significantly $(\mathrm{p}<0.05)$ to sucrose $[300 \mathrm{mM}]$, D-glucose $[150 \mathrm{mM}]$, maltodextrin $[8 \%], \alpha$-mgp [150mM, sucralose [15mM], and acesulfame K [15mM] ( $\mathrm{n} \geq 5$ wild-type mice per group; quantified in Extended Data 1). Fructose $[150 \mathrm{mM}]$ and saccharin $[15 \mathrm{mM}]$ responses are not significant $(\mathrm{p}>0.05)$. $\mathbf{c}$, Model: duodenal epithelial cells are known to express SGLT1 and T1R2/3 which are inhibited by phloridzin and gurmarin, respectively. d, Vagal responses to intra-duodenal sucrose $[300 \mathrm{mM}]$ and $\alpha-M G P[150 \mathrm{mM}]$ are inhibited by SGLT1 inhibitor phloridzin $[3 \mathrm{mM}]$ and to sucralose $[15 \mathrm{mM}]$ by the T1R2/3 inhibitor gurmarin $[7 \mu \mathrm{M}]$. e, Quantification of e; $(\mathrm{n} \geq 5$ mice per group; * $<<0.0001$, ANOVA with post-hoc Tukey's HSD test). Gray vertical bars indicate infusion period.

Shaded regions on traces or error bars indicate SEM.

discovered that intestinal neuropod cells transduce a D-glucose stimulus to vagal neurons in milliseconds. ${ }^{10}$ But it is unknown if this neuroepithelial circuit can distinguish the sweetness and caloric value of sugars.

Vagal nodose neurons alone do not respond to sugars. 58 of 59 dissociated neurons showed no calcium transients in response to D-glucose [20mM], maltodextrin [1\%], or sucralose [2mM]. All neurons responded to $\mathrm{KCl}$ [50mM], confirming their viability ( $\mathrm{n}=59$ neurons; Extended Data Fig. 3a). A supplementary single cell sequencing analysis showed that nodose neurons lack the expression of Tas1r2, Tas1r3, and the SGLT1 transcript Slc5a1 (N $\geq 5$ left and right nodose ganglia, Extended Data Fig. 3b). T1R2, T1R3 and SGLT1 do, however, colocalize with intestinal epithelial cells immunoreactive for the cholecystokinin neuropeptide. ${ }^{23,28}$ 
bioRxiv preprint doi: https://doi.org/10.1101/2020.03.06.981365; this version posted March 8, 2020. The copyright holder for this preprint (which was not certified by peer review) is the author/funder. All rights reserved. No reuse allowed without permission.

a Photoinhibition

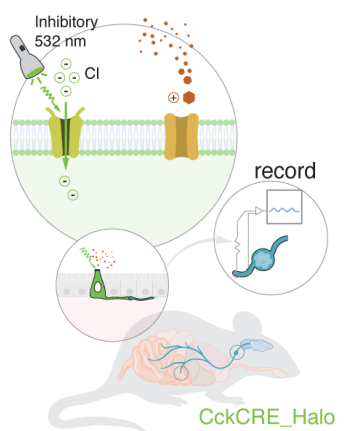

b Vagal responses to sugars depend on neuropod cells

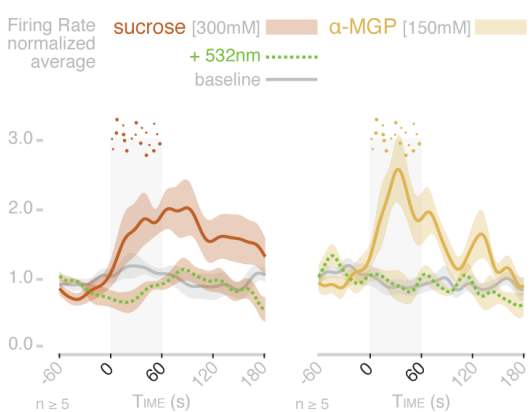

sucralose $[15 \mathrm{~mm}] \mathrm{ln}=$
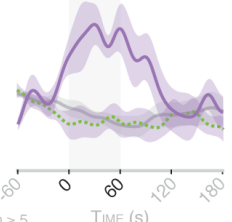

C Quantification

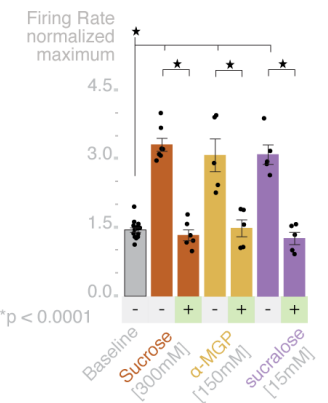

d Single-cell qRTPCR of synaptic genes and sugar receptors

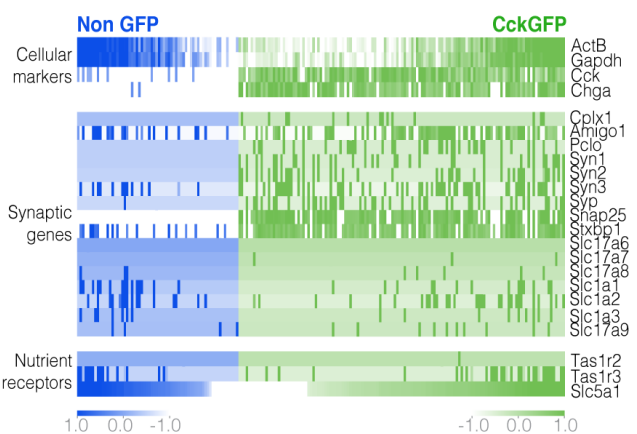

e SGLT1 and taste receptors in single neuropod cells

$$
100 \% \text {. CckGFP cells }
$$

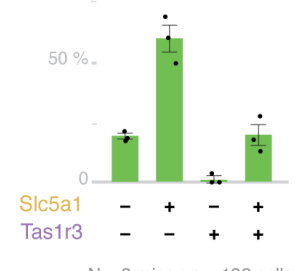

f Sugar sensing

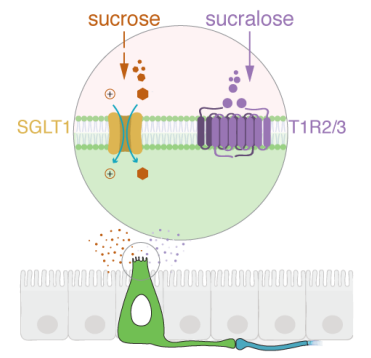

$N=3$ mice $: n=132$ cells
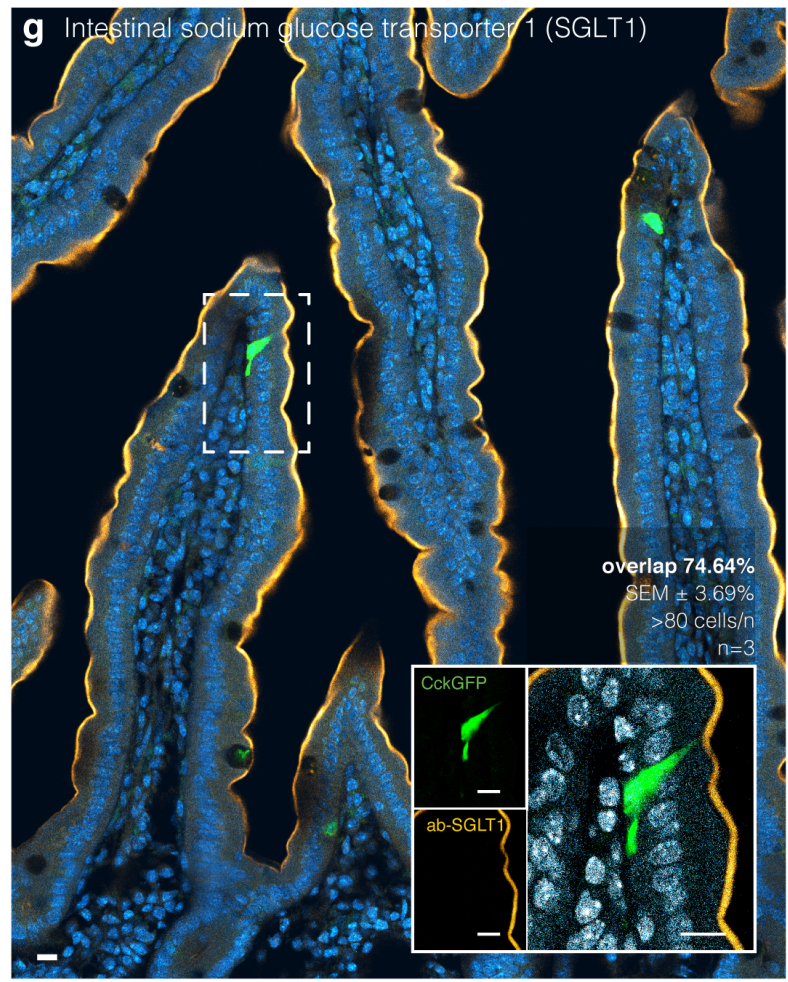

h Ca $^{2+}$ imaging of Cck neuropods
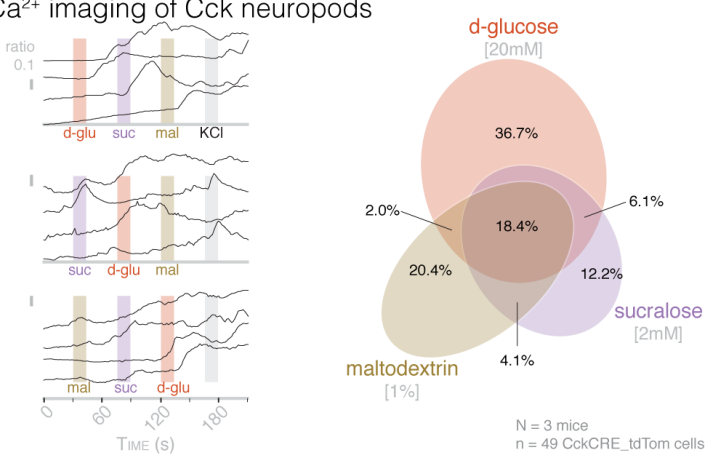

i Whole cell patch clamp of co-cultured vagal neurons
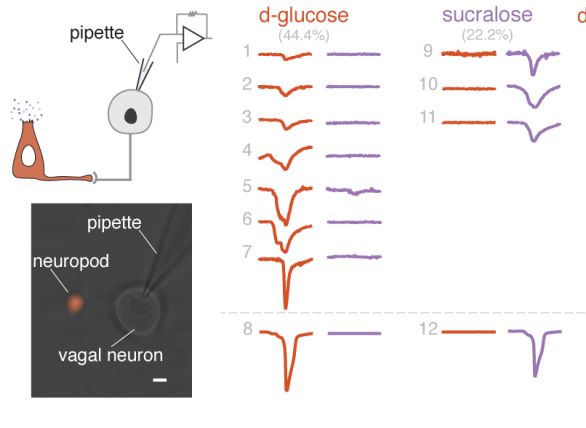

ucose \& sucralose
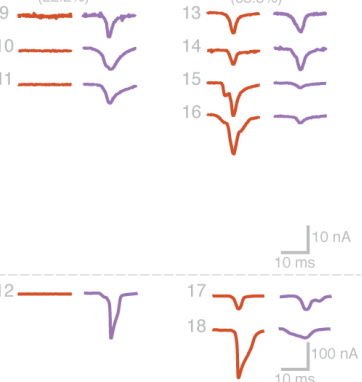
Fig. 2. Neuropod cells sort caloric sugars from non-caloric sweeteners. a, Model: intraluminal 532nm laser activates Halorhodopsin chloride channels to silence duodenal neuropod cells in CckCRE_Halo mice. b, Silencing duodenal CckCRE_Halo cells eliminates vagal responses to sucrose [300mM], $\alpha$-mgp [150mM], and sucralose $[15 \mathrm{mM})$. c, Quantification of $\mathrm{b}(\mathrm{n} \geq 5$ mice per group; $* \mathrm{p}<0.0001$, ANOVA with post-hoc Tukey's HSD test). Gray vertical bars indicate infusion period. d, Single cell qRT-PCR of CckGFP cells and non-GFP intestinal epithelial cells. Compared to non-GFP epithelial cells $(\mathrm{n}=66)$, CckGFP cells $(\mathrm{n}=132)$ overexpress presynaptic genes Cplx1, Amigo1, Pclo, Syn1, Syn3, Syp, Snap25, Stxbp1 (N=3 mice; q=0.01). e, Of 132 CckGFP cells, $19.1 \pm 1.2 \%$ express transcripts for neither Slc5a1 (SGLT1) nor Tas $1 r 3$ (T1R3), $60.1 \pm 5.7 \%$ for only Slc $5 a 1,1.2 \pm 1.2 \%$ for only Tas $1 r 3$, and $19.6 \pm 4.3 \%$ for both, $(\mathrm{n}=3$ mice). f, Model: neuropod cells express SGLT1 and T1R2/3 to sense sugars. g, 3 out of 4 CckGFP cells (green) in the duodenum express SGLT1 (yellow) ( $\mathrm{n}=80-100$ cells per mouse, $\mathrm{N}=3$ mice). Scale bars, $10 \mu \mathrm{m}$. $\mathbf{h}$, Intestinal CckCRE tdTomato cells loaded with Fluo-4/FuraRed respond to D-glucose [20mM], sucralose [2mM], and maltodextrin [1\%]. Leftrepresentative traces; right- Venn diagram. ( $\mathrm{n}=3$ mice, $\mathrm{n}=49$ cells). $\mathrm{i}$, Left- Patch-clamp electrophysiology of

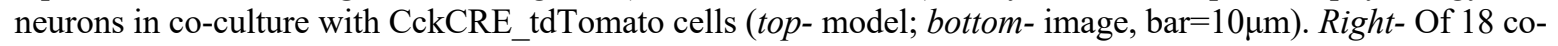
culture pairs, excitatory post-synaptic potentials were recorded in neurons in response to D-glucose $(20 \mathrm{mM}$, $44.4 \%)$, to sucralose (2mM, 22.2\%), and to both (33.3\%). Shaded regions on traces and error bars indicate SEM.

Intestinal neuropod cells are labeled by the promoter for cholecystokinin., ${ }^{5,10}$ This neuropeptide only participates in the prolonged vagal responses to D-glucose minutes after the initial stimulus. ${ }^{10}$ To determine if neuropod cells rapidly sort sugar stimuli, we used optogenetics. Using Cre-loxP recombination, we bred a CckCRE_Halo mouse in which neuropod cells expressed the chloride pump halorhodopsin (Fig. 2a). When triggered by $532 \mathrm{~nm}$ light, halorhodopsin hyperpolarizes the cell membrane, silencing electrically excitable cells instantly. In CckCRE_Halo mice, vagal responses to luminal sucrose, $\alpha$-mgp, and sucralose were abolished in the presence of 532nm light $(\mathrm{n} \geq 5, \mathrm{p}<0.001 ;$ Fig. $2 \mathrm{~b}$-c). Vagal responses remained intact in the presence of the control $473 \mathrm{~nm}$ light. ${ }^{10}$ Thus, neuropod cells are necessary to transduce both caloric and non-caloric sugar stimuli.

Taste and calorie sorted. Receptors for both caloric and non-caloric sugars were expressed in individual CckGFP cells. Tas $1 r 2$ was negligible, Tas $1 r 3$ alone was in 1.2\% ( \pm 1.2$)$, Tas $1 r 3$ and the SGLT1 transcript Slc5al were in $19.6 \%( \pm 4.3)$, and the SGLT1 transcript Slc5al alone was in $60.1 \%( \pm 5.7)(\mathrm{N}=3$ mice, $\mathrm{n}=132$ CckGFP cells; Fig. 2d-f). Accordingly, SGLT1 was immunoreactive in $74.6 \%( \pm 3.7)$ of CckGFP cells $(\mathrm{N}=3$ mice; $\mathrm{n} \geq 80$ cells per mouse; Fig. $2 \mathrm{~g})$. Moreover, compared to other intestinal epithelial cells, Slc5al positive CckGFP cells had significantly increased expression of the pre-synaptic genes Efnb2 (fold change 81.6) and Cask (fold change 30.2), and the synaptic adhesion genes Pvrll (fold change 31.05) and Pvrl2 (fold change 35.2) $\left(\mathrm{n}=104\right.$ Slc5a1 + CckGFP+ cells, $\mathrm{n}=28$ Slc5al- CckGFP+ cells; $\left.{ }^{*} \mathrm{p}<0.0001\right)$ (Fig. 2d). Synaptic molecules are a feature of fast acting neuropod cells. ${ }^{5,10}$

We determined if individual neuropod cells respond to both sweet and caloric sugars. Using calcium imaging, we recorded responses from individual Cck_tdTomato cells. Stimuli were applied in sequence and alternated in replicate experiments to account for potential priming or inhibitory effects. Cell viability was confirmed using $\mathrm{KCl}[50 \mathrm{mM}]$. Responses were as follows: $36.7 \%$ responded to D-glucose alone $[20 \mathrm{mM}], 20.4 \%$ to maltodextrin alone [ $1 \%], 12.2 \%$ to sucralose alone $[2 \mathrm{mM}]$, and $18.4 \%$ to all three sugars $(\mathrm{N}=3$ mice, $\mathrm{n}=49$ cells; Fig. $2 \mathrm{~h})$. To determine if these responses are represented in connected vagal neurons in the absence of other cell types, we co-cultured Cck_tdTomato cells with nodose neurons. In vitro, neuropod cells synapse with vagal neurons. $5,1 \overline{0}$ 
a Neurotransmission

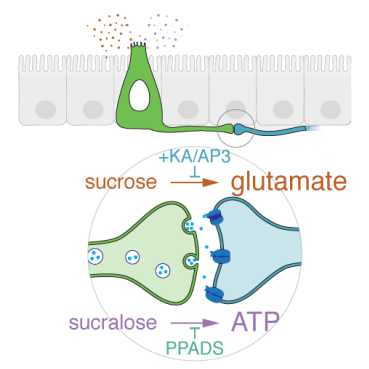

b Sucrose entry into neuropod cells causes release of glutamate
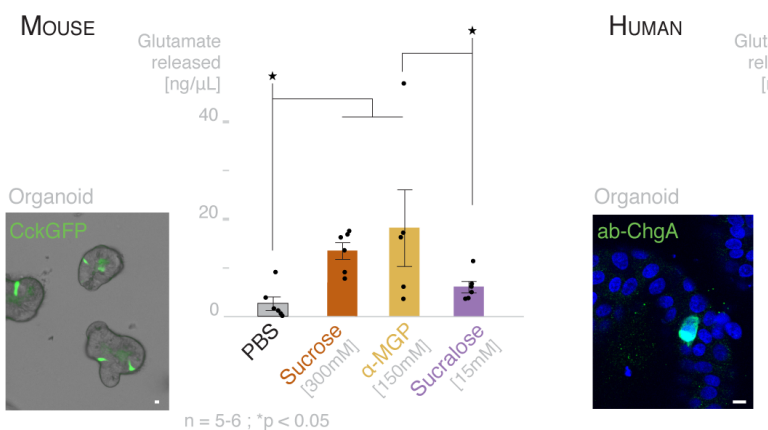

$\theta$

C Sucralose signal is transduced to the vagus nerve through purinergic signaling
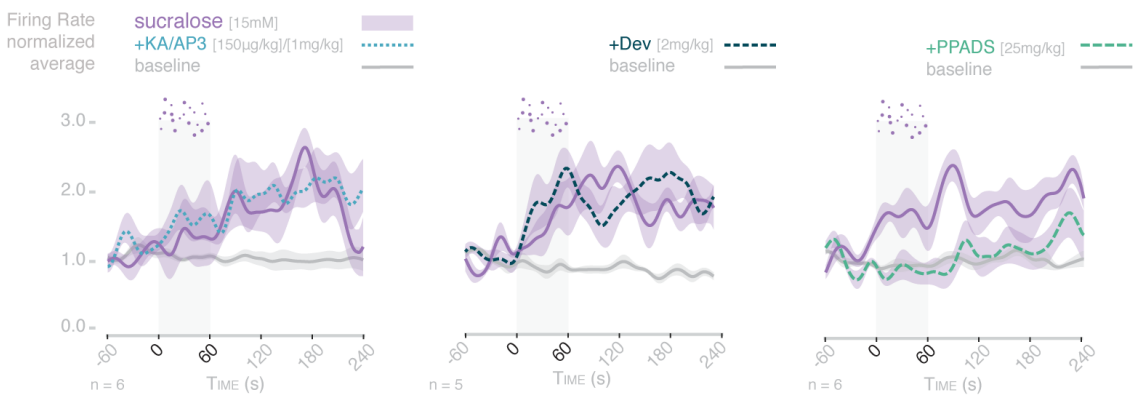

e Entry of calorie through SGLT1 drives glutamatergic neurotransmission
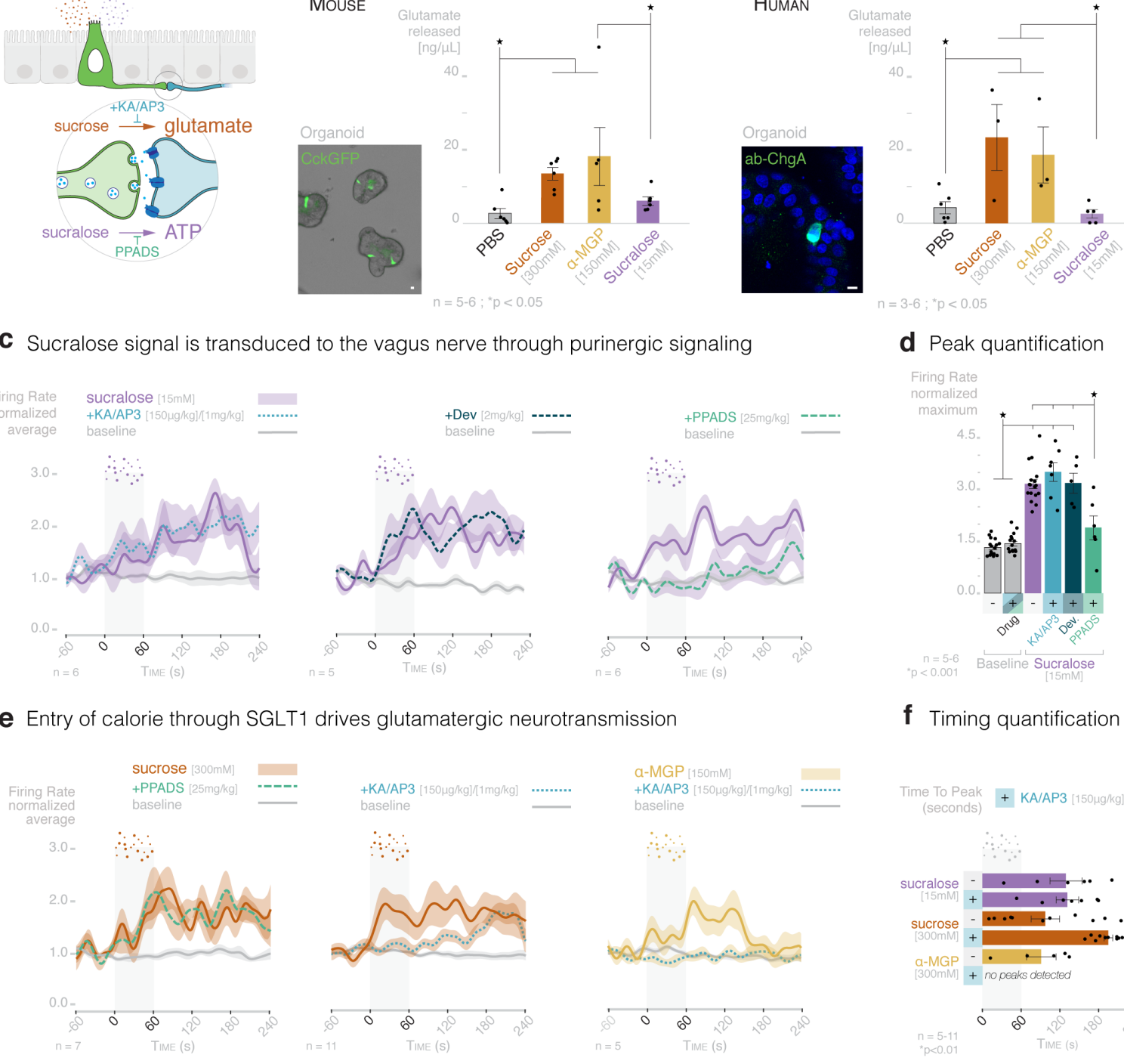

\section{d Peak quantification}

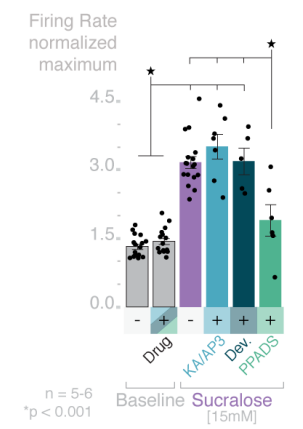

f Timing quantification

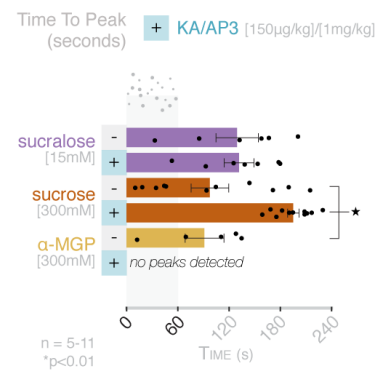

Fig. 3. Sucralose leads to ATP release, whereas the entry of sucrose via SGLT1 stimulates glutamate release. a, Model: neuropod cells transduce caloric and non-caloric sugar signals to the vagus nerve using differential neurotransmitter release. b, Left- In CckGFP mouse intestinal organoids (CckGFP, green), sucrose $[300 \mathrm{mM}]$ and $\alpha \mathrm{MGP}[150 \mathrm{mM}]$ elicit significant glutamate release compared to PBS control, while sucralose $[15 \mathrm{mM}]$ does not $\left(\mathrm{n}=5-6\right.$ plates, $\mathrm{N}=3$ mice, ${ }^{*} \mathrm{p}<0.05$ by Student's t-test). Right- Human duodenal organoids contain Chromogranin-A+ cells (ChgA, green) and release glutamate in response to sucrose and $\alpha$ MGP, but not to sucralose or PBS control ( $\mathrm{n}=3-6$ plates, $\mathrm{N}=1$ human sample, ${ }^{*} \mathrm{p}<0.05$ by Student's t-test). $\mathbf{c}$, The rapid vagal response to sucralose $[15 \mathrm{mM}]$ is not attenuated by inhibition of ionotropic/metabotropic glutamate receptors with KA/AP3 $[150 \mu \mathrm{g} / \mathrm{kg}] /[1 \mathrm{mg} / \mathrm{kg}]$ or by inhibition of Cck-A receptors with devazepide $[2 \mathrm{mg} / \mathrm{kg}]$; rather, it is ATP-dependent (attenuated by non-selective P2 purinoceptor inhibition with PPADS [25mg/kg]). d, Quantification of c ( $\mathrm{n}=5-6$ mice, ${ }^{*} \mathrm{p}<0.001$ ANOVA with post hoc Tukey's HSD test). e, While inhibition of P2 purinoreceptors does not affect the response to sucrose, the fast vagal response to sucrose $[300 \mathrm{mM}]$ and the entire response to $\alpha$-MGP $[150 \mathrm{mM}]$ are abolished by glutamate receptor inhibition with KA/AP3. f, Glutamate receptor inhibition prolonged the time to peak vagal firing rate in response to sucrose but not sucralose. No increase in vagal firing rate was detected for $\alpha$-MGP after glutamate receptor inhibition ( $\mathrm{n}=5-11$ mice, ${ }^{*} \mathrm{p}<0.01$ ANOVA with post hoc Tukey's HSD test). Shaded regions on traces or error bars indicate SEM. Scale bars, $10 \mu \mathrm{m}$. 
We recorded activity from connected neurons using voltage- clamp electrophysiology. D-glucose and sucralose stimuli were applied to the bath solution in alternating order (Fig. 2i). We observed excitatory post-synaptic currents in connected neurons as follows: $44.4 \%$ to D-glucose alone, $22.2 \%$ to sucralose alone, and $33.3 \%$ to both sucrose and sucralose ( $n=18$ pairs, Fig. $2 \mathrm{i}$ ). Peak current in the connected neurons was not statistically different for either stimulus (Extended Data Fig. 3d), suggesting that two separate paths, of similar synaptic strength, are elicited by the sweet and caloric stimuli sensed by neuropod cells.

The messengers. D-glucose causes the release of glutamate from neuropod cells. ${ }^{10}$ These cells express transcripts for the vesicular glutamate transporters Slc17a7, Slc17a8 and the synaptic glutamate transporters Slcla1, Slcla2, and Slcla3 (Fig. 2d). In addition, vagal neurons express transcripts for both metabotropic and ionotropic glutamate receptors (Extended Data Fig. 3e). But it remained to be determined whether both sweet taste and caloric sugars trigger glutamate release (Fig. 3a).

We tested glutamate release by culturing organoids from mouse proximal small intestine ${ }^{29}$ and human duodenum. ${ }^{30}$ In both mouse and human organoids, sucrose $[300 \mathrm{mM}]$ and $\alpha-\mathrm{mgp}$ $[150 \mathrm{mM}]$ elicited a significant release of glutamate compared to PBS $(\mathrm{N}=3$ mice, $\mathrm{n} \geq 5$ organoid wells in triplicate per stimuli, $\mathrm{p}<0.05$, Fig. 3b-left; $\mathrm{N}=1$ human patient donor, $\mathrm{n} \geq 3$ organoid wells in triplicate per stimuli, $p<0.05$, Fig. 3b-right). Sucralose $[15 \mathrm{mM}]$ did not stimulate glutamate release (Fig. 3b; Extended Data Fig. 4a).

In fact, the vagal response to sucralose remained intact when glutamate receptors were blocked using an intraluminal injection of AP3 [1mg/kg] plus kynurenic acid [150 $\mu \mathrm{g} / \mathrm{kg}]$ (Fig. 3c-d). Although vagal neurons express the cholecystokinin A receptor, the vagal response to sucralose remained intact even when blocking cholecystokinin signaling with devazepide ${ }^{17}[2 \mathrm{mg} / \mathrm{kg}]$ (Fig. 3c-d; Extended Data Fig. 3e, 4b). In other sensory transducers, like taste receptor cells in the tongue, sweet stimuli are transduced onto to afferent nerves using vesicular ATP. ${ }^{31}$ We observed that vagal nodose neurons express ATP purinergic receptors and CckGFP cells express the Slc17a9 transcript for the vesicular nucleotide transporter (Extended Data Fig. 3e; Fig. 2d). Indeed, by inhibiting purinergic receptors with PPADS $[25 \mathrm{mg} / \mathrm{kg}]$, vagal responses to sucralose were significantly attenuated. This indicates that sweet sucralose is transduced by neuropod cells using ATP as a neurotransmitter (p<0.05, Fig. 3c-d; Extended Data Fig. 4e-f).

It is the entry of the sugar. Inhibiting ATP neurotransmission did not affect the vagal response to sucrose or $\alpha$-mgp (Fig. 3e-f, Extended Data Fig.4d-f). Instead, the entire $\alpha$-mgp response and the first 120 seconds of the sucrose response were abolished by blocking glutamate neurotransmission (Fig. 3e-f; Extended Data Fig. 4c). If the $\alpha$-mgp response completely depends on glutamatergic neurotransmission and $\alpha$-mgp enters the cell through SGLT1, then the entry of the sugar through SGLT1 is sufficient to drive glutamatergic neurotransmission between neuropod cells and vagal neurons. We wondered if this neuropod cell mechanism is responsible for the animals' innate preference of caloric sugars over non-caloric sweeteners.

Timing sugar preferences. To determine the timing of the behavioral response in seconds, without perturbing the animal's natural behavior, we optimized an automated phenotyping system called PhenoMaster (Fig. 4a-b). Each PhenoMaster cage holds one mouse and two gated 
a Preference assay sucrose vs. sucralose

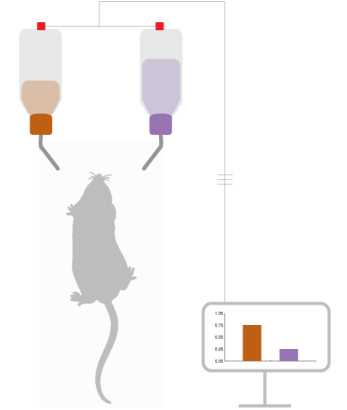

C Fiber engineering

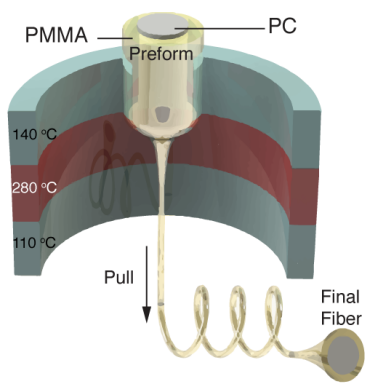

b Mice choose to ingest sucrose over sucralose within minutes

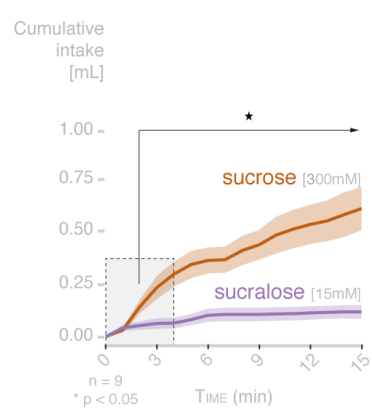

d Flexibility verification

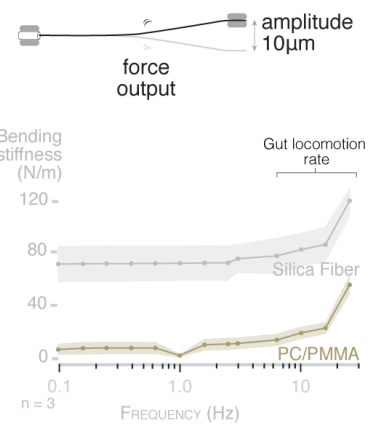

e Gut intraluminal optogenetics in awake and behaving mice

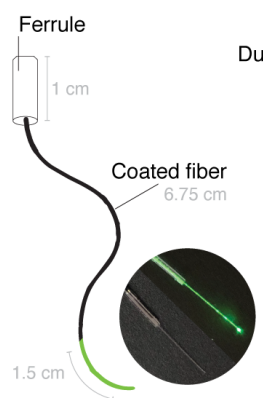

g Quantification

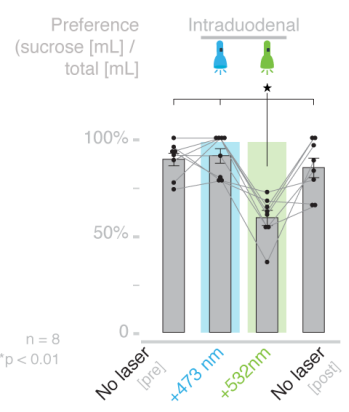

j Quantification

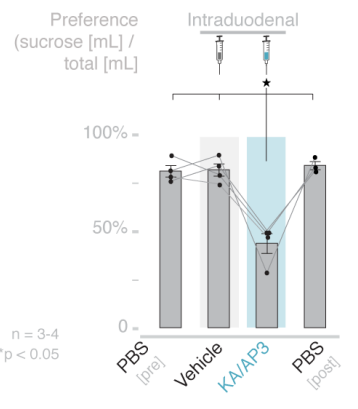

h Total intake

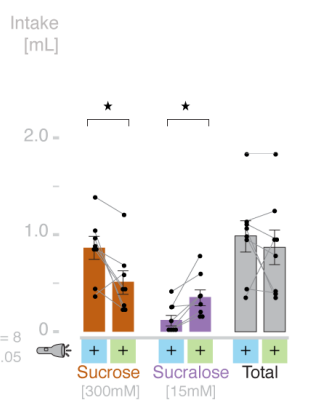

k Total intake

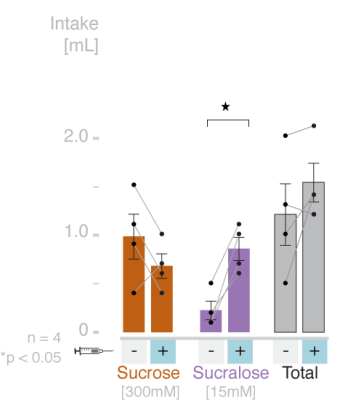


Fig. 4. Intestinal neuropod cells drive choice for sucrose over sucralose. a, Model: mice choose between sucrose $[300 \mathrm{mM}]$ or sucralose $[15 \mathrm{mM}]$ while consumption is recorded every 5 seconds. b, Within 2.08 minutes, wild-type mice develop sucrose preference $\left(n=9\right.$ mice, ${ }^{*} \mathrm{p}<0.05$, repeated-measures ANOVA with post-hoc paired t-test). c, Schematic: thermal drawing process for the flexible PC/PMMA waveguide fiber. Application of controlled stress and heat reduces diameter $\sim 40$ fold. d, Flexibility of standard silica and PC/PMMA fiber was measured by a dynamic mechanical analyzer in single cantilever mode with a displacement amplitude of $10 \mu \mathrm{m}$ at physiologic frequencies ( $n=3$ fibers, shaded regions represent SD). e, Four weeks after intraduodenal implantation, the flexible fiberoptic continues to illuminate. f, Compared to $473 \mathrm{~nm}$ control laser, silencing duodenal neuropod cells with 532nm laser in CckCRE_NpH3 mice eliminates sucrose preference. g, Preference quantified at one hour with no (pre/post), 473nm (control), and 532nm (silencing) laser. h, Silencing neuropod cells decreases sucrose and increases sucralose consumption but does not affect total consumption. $\mathbf{i}$, In wildtype mice, intraduodenal perfusion of KA/AP3 [ $5 \mathrm{ng} / 0.1 \mu \mathrm{g}$ in $0.4 \mathrm{~mL}$ over 1 hour] to inhibit local glutamate receptors eliminates sucrose preference. $\mathbf{j}$, Preference quantified at 1 hour with PBS (pre/post), vehicle (PBS+NaOH, pH 7.4), and glutamate receptor blockers KA/AP3. k, Inhibiting glutamate receptors increases sucralose consumption without significantly affecting sucrose or total consumption (for $\mathrm{f}-\mathrm{h}$ : $\mathrm{n}=8$; for $\mathrm{i}-\mathrm{k}$ : $\mathrm{n}=4$; $* \mathrm{p}<0.05$, repeated-measures ANOVA with post-hoc paired t-test). Shaded regions or error bars indicate SEM unless otherwise indicated.

bottles that are constantly weighed with a time resolution of 5 seconds. We gave the mouse a choice between iso-sweet sucrose $[300 \mathrm{mM}]$ and sucralose $[15 \mathrm{mM}]$. When the gates opened, experienced mice showed a robust and significant preference for sucrose within $\sim 125$ seconds $(\mathrm{p}$ $<0.05, \mathrm{n}=9$ mice; Fig. $4 \mathrm{~b}$ ). Now we needed a method to record the mouse's preferences while its neuropod cells are rapidly "switched on or off".

In the brain, the contribution of specific neural circuits to behaviors has been widely explored using light-sensitive opsins triggered with laser light delivered via fiberoptic cables. But in the gut, the rigid silica fiberoptics suitable for the mouse brain puncture and perforate the delicate intestinal lumen. We learned rather quickly that flexibility is a must.

The illumenator. To illuminate the intestines of awake and behaving mice, we envisioned a flexible fiberoptic waveguide fiber with the following properties: (1) thin in diameter for minimal footprint within the intestinal lumen, 2) low optical loss coefficient, and 3) durable for months when flexed and bent inside the churning gut. We engineered a template of a polymethyl methacrylate (PMMA) cladding layer around an optical core of polycarbonate (PC). The template was consolidated using thermal drawing process ${ }^{32,33}$ and pulled at $270^{\circ} \mathrm{C}$ into a final flexible fiberoptic of only $230 \mu \mathrm{m}$ in diameter (Fig. 4c; Extended Data Fig. 5a). Compared to rigid silica fibers, the flexible fiberoptic bends and does not pierce through even a soft layer of $1.5 \%$ agarose (Extended Data Fig. 5b, Video 1). The device efficiently transmits light and tolerates rapid bending at $10 \mathrm{~Hz}$, which is above the physiological frequency of gut motility (Fig. 4d; Extended Data Fig. 5c-e). We called the device the illumenator.

Prior to implantation, we enclosed the illumenator in an opacified microrenathane sheath to restrict the delivery of the light only to a portion of the tip end (Fig. 4e). When implanted, this feature allowed us to target the light only to the first $1.5 \mathrm{~cm}$ of the mouse small intestine. We confirmed the device's durability by implanting it in the intestine of CckCRE_Halo mice. Four weeks later, a 532nm light stimulus emitted from the device was sufficient to abolish normal vagal responses to sucrose perfused into the duodenum (Extended Data Fig.5f).

We implanted mice with the illumenator to test sugar preferences (Fig. 4e). Each mouse was acclimated for neophobia, tested for side preference, and the location and power of the implanted 
device were corroborated at the end of the study (see methods). On each experimental day, implanted mice were given the choice between sucrose and sucralose for 1 hour while receiving laser stimulation ( $1 \mathrm{~min}$ on $/ 2 \mathrm{~min}$ off, $5 \mathrm{~V}, 40 \mathrm{~Hz}, 20 \%$ duty cycle). Sucrose and sucralose intake were recorded at 5 second intervals. Locomotor activity was recorded throughout the study, and chow and water intake were recorded for 24 hours following the assay to control for malaise.

Neuropods drive sugar preference. In CckCRE_Halo mice, silencing duodenal neuropod cells with $532 \mathrm{~nm}$ light completely abolished the innate preference for sucrose. In the presence of $532 \mathrm{~nm}$ light, negative littermates showed $90.8 \%( \pm 3.74)$ sucrose preference, whereas CckCRE_Halo mice only showed 58.9\% ( \pm 3.92) $(\mathrm{n} \geq 5, \mathrm{p}<0.01$; Fig. 4f-g, Extended Data Fig. $6 \mathrm{~d}-\mathrm{e})$. Silencing neuropod cells did not affect chow or water intake in the following 24 hours, or locomotor activity during the assay, indicating no malaise effects (Extended Data Fig. 6a-c). Nor did it affect the total consumption of liquid during the hour test. Instead, it reduced sucrose intake and increased sucralose intake ( $<<0.05$; Fig. 4h, Extended Data Fig. 6f). Sucrose preference was not affected by blocking cholecystokinin receptors with intraperitoneal devazepide (Extended Data Fig. 7a-d). ${ }^{17}$

We wondered if glutamate is the transmitter for sucrose preference. A catheter was implanted into the mouse's duodenal lumen to deliver a low dose of the glutamate receptor blockers, AP3 plus kynurenic acid $[0.1 \mu \mathrm{g} / 5 \mathrm{ng}$ in $0.4 \mathrm{~mL}]$. Mice underwent the same inclusion analysis as those implanted with the illumenator. Sucrose preferences in mice receiving a vehicle control was $82.4 \%( \pm 3.20)$, whereas in mice receiving intraduodenal glutamatergic inhibitors, sucrose preference was significantly reduced to $44.0 \%( \pm 5.19)(n=4, p<0.05$; Fig. 4i-j). No malaise effects were observed. Blocking glutamatergic neurotransmission also increased sucralose intake without significantly changing total intake (Fig. 4k). In the absence of the neuropod cell glutamatergic input, the animal could not distinguish the caloric sugar from the non-caloric sweetener.

If so, could exciting neuropod cells increase sucralose intake? We bred mice in which neuropod cells express channelrhodopsin 2 (ChR2). ChR2 depolarizes electrically excitable cells instantly if stimulated with $473 \mathrm{~nm}$ light. In this test, intake was paired to laser stimulation $(0.01 \mathrm{~mL}$ intake caused 5 seconds stimulation; $5 \mathrm{~V}, 40 \mathrm{~Hz}, 20 \%$ duty cycle). When presented with one bottle of sucralose, CckCRE_ChR2 mice significantly increased their intake if their duodenal neuropod cells were excited with 473nm light. Exciting neuropod cells increased the mouse's intake of sucralose to its innate level of sucrose $(n=4, p<0.05$; Extended Data Fig. 8a-c). Thus, neuropod cells drive sugar intake and preference.

A gut choice. In his classic book Behave, the neuroendocrinologist Robert Sapolsky states "What occurred in the prior seconds to minutes that triggered the nervous system to produce the behavior, this is the world of sensory stimuli, much of it sensed unconsciously." 34 By sensing the entrance of sugar, neuropod cells have the responsibility to advise the nervous system to steer the animal towards the sugar with the caloric value, even before consciousness has settled. This work is a foundation to understand how the nutritive value of other ingested macronutrients, and perhaps micronutrients, are sensed by the gut to aid the brain in choosing what to put in our mouth. 


\section{References}

1. Miller, N. E. \& Kessen, M. L. Reward effects of food via stomach fistula compared with those of food via mouth. J. Comp. Physiol. Psychol. 45, 555-564 (1952).

2. Sclafani, A. Post-ingestive positive controls of ingestive behavior. Appetite 36, 79-83 (2001).

3. de Araujo, I. E. et al. Food Reward in the Absence of Taste Receptor Signaling. Neuron (2008) doi:10.1016/j.neuron.2008.01.032.

4. Han, W. et al. Striatal Dopamine Links Gastrointestinal Rerouting to Altered Sweet Appetite. Cell Metab. 23, 103-112 (2016).

5. Bohórquez, D. V. et al. Neuroepithelial circuit formed by innervation of sensory enteroendocrine cells. J. Clin. Invest. 125, 782-786 (2015).

6. Williams, E. K. K. et al. Sensory Neurons that Detect Stretch and Nutrients in the Digestive System. Cell (2016) doi:10.1016/j.cell.2016.05.011.

7. Su, Z., Alhadeff, A. L. \& Betley, J. N. Nutritive, Post-ingestive Signals Are the Primary Regulators of AgRP Neuron Activity. Cell Rep. (2017) doi:10.1016/j.celrep.2017.11.036.

8. Beutler, L. R. et al. Dynamics of Gut-Brain Communication Underlying Hunger. Neuron (2017) doi:10.1016/j.neuron.2017.09.043.

9. Bohórquez, D. V. et al. Neuroepithelial circuit formed by innervation of sensory enteroendocrine cells. J. Clin. Invest. 125, (2015).

10. Kaelberer, M. M. et al. A gut-brain neural circuit for nutrient sensory transduction. Science (80-. ). (2018) doi:10.1126/science.aat5236.

11. Han, W. et al. A Neural Circuit for Gut-Induced Reward. Cell 175, 665-678.e23 (2018).

12. Damak, S. Detection of Sweet and Umami Taste in the Absence of Taste Receptor T1r3. Science (80-. ). 301, 850-853 (2003).

13. Domingos, A. I. et al. Leptin regulates the reward value of nutrient. Nat. Neurosci. 14, 1562-1568 (2011).

14. Sclafani, A. \& Ackroff, K. Operant licking for intragastric sugar infusions: Differential reinforcing actions of glucose, sucrose and fructose in mice. Physiol. Behav. 153, 115-124 (2016).

15. Booth, D. A. Satiety and behavioral caloric compensation following intragastric glucose loads in the rat. J. Comp. Physiol. Psychol. 78, 412-432 (1972).

16. Dus, M., Min, S. H., Keene, A. C., Lee, G. Y. \& Suh, G. S. B. Taste-independent detection of the caloric content of sugar in Drosophila. Proc. Natl. Acad. Sci. U. S. A. (2011) doi:10.1073/pnas.1017096108.

17. Pérez, C., Lucas, F. \& Sclafani, A. Devazepide, a CCK(A) antagonist, attenuates the satiating but not the preference conditioning effects of intestinal carbohydrate infusions in rats. Pharmacol. Biochem. Behav. 59, 451-457 (1998).

18. Mei, N. Vagal glucoreceptors in the small intestine of the cat. J. Physiol. (1978) doi:10.1113/jphysiol.1978.sp012477.

19. Sclafani, A. \& Ackroff, K. Operant licking for intragastric sugar infusions: Differential reinforcing actions of glucose, sucrose and fructose in mice. Physiol. Behav. 153, 115-124 (2016).

20. Crane, R. K. Intestinal Absorption of Sugars. Physiol. Rev. 40, 789-825 (1960).

21. Reimann, F. et al. Glucose Sensing in L Cells: A Primary Cell Study. Cell Metab. 8, 532539 (2008).

22. Sclafani, A., Koepsell, H. \& Ackroff, K. SGLT1 sugar Transporter/Sensor is required for 
post-oral glucose appetition. Am. J. Physiol. - Regul. Integr. Comp. Physiol. (2016) doi:10.1152/ajpregu.00432.2015.

23. Dyer, J., Salmon, K. S. H., Zibrik, L. \& Shirazi-Beechey, S. P. Expression of sweet taste receptors of the T1R family in the intestinal tract and enteroendocrine cells. Biochem. Soc. Trans. 33, 302-305 (2005).

24. Ninomiya, Y.\& Imoto, T. Gurmarin inhibition of sweet taste responses in mice. Am. J. Physiol. - Regul. Integr. Comp. Physiol. 268, (1995).

25. Ehrenkranz, J. R. L., Lewis, N. G., Kahn, C. R. \& Roth, J. Phlorizin: A review. Diabetes. Metab. Res. Rev. 21, 31-38 (2005).

26. Bellono, N. W. et al. Enterochromaffin Cells Are Gut Chemosensors that Couple to Sensory Neural Pathways. Cell 170, 185-198.e16 (2017).

27. Lu, V. B. et al. Adenosine triphosphate is co-secreted with glucagon-like peptide-1 to modulate intestinal enterocytes and afferent neurons. Nat. Commun. 10, (2019).

28. Daly, K. et al. Sensing of amino acids by the gut-expressed taste receptor T1R1-T1R3 stimulates CCK secretion. Am. J. Physiol. - Gastrointest. Liver Physiol. (2013) doi:10.1152/ajpgi.00074.2012.

29. Sato, T. et al. Single Lgr5 stem cells build crypt-villus structures in vitro without a mesenchymal niche. Nature 459, 262-265 (2009).

30. Fujii, M., Matano, M., Nanki, K. \& Sato, T. Efficient genetic engineering of human intestinal organoids using electroporation. Nat. Protoc. 10, 1474-1485 (2015).

31. Finger, T. E. ATP Signaling Is Crucial for Communication from Taste Buds to Gustatory Nerves. Science (80-. ). 310, 1495-1499 (2005).

32. Canales, A. et al. Multifunctional fibers for simultaneous optical, electrical and chemical interrogation of neural circuits in vivo. Nat. Biotechnol. 33, 277-284 (2015).

33. Park, S. et al. One-step optogenetics with multifunctional flexible polymer fibers. Nat. Neurosci. 20, 612-619 (2017).

34. Sapolsky, R. M. Behave : the biology of humans at our best and worst. (Penguin Press, 2017).

35. Wang, Y. et al. Amino acids stimulate cholecystokinin release through the Ca $2+-$ sensing receptor . Am. J. Physiol. Liver Physiol. 300, G528-G537 (2010).

36. Sato, T. et al. Single Lgr5 stem cells build crypt-villus structures in vitro without a mesenchymal niche. Nature 459, 262-5 (2009).

37. Saxena, K. et al. Human Intestinal Enteroids : a New Model To Study Human. J. Virol. 90, 43-56 (2016).

38. Nawrot, M., Aertsen, A. \& Rotter, S. Single-trial estimation of neuronal firing rates: From single-neuron spike trains to population activity. J. Neurosci. Methods 94, 81-92 (1999).

39. Sigoillot, M., Brockhoff, A. \& Meyerhof, W. Sweet-taste-suppressing compounds : current knowledge and perspectives of application. 619-630 (2012) doi:10.1007/s00253012-4387-3.

40. Ohkuri, T. et al. Multiple sweet receptors and transduction pathways revealed in knockout mice by temperature dependence and gurmarin sensitivity. Am J Physiol Regul Integr Comp Physiol 296, R960-R971 (2009).

41. Beutler, L. R. et al. Dynamics of Gut-Brain Communication Underlying Hunger. Neuron 96, 461-475.e5 (2017).

42. Bäckström, P. \& Hyytiä, P. Ionotropic Glutamate Receptor Antagonists Modulate CueInduced Reinstatement of Ethanol-Seeking Behavior. Alcohol. Clin. Exp. Res. 28, 558- 
565 (2004).

43. Shang, Y. et al. Fragile X mental retardation protein is required for chemically-induced long-term potentiation of the hippocampus in adult mice. J. Neurochem. 111, 635-646 (2009).

44. Rong, W., Burnstock, G. \& Spyer, K. M. P2X purinoceptor-mediated excitation of trigeminal lingual nerve terminals in an in vitro intra-arterially perfused rat tongue preparation. J. Physiol. 524, 891-902 (2000).

45. Ribeiro, T. et al. Blockade of ATP P2X7 receptor enhances ischiatic nerve regeneration in mice following a crush injury. Brain Res. 1669, 69-78 (2017).

46. Borsani, E. et al. PPADS, a purinergic antagonist reduces Fos expression at spinal cord level in a mouse model of mononeuropathy. Brain Res. 1199, 74-81 (2008).

47. Ståhlberg, A., Rusnakova, V., Forootan, A., Anderova, M. \& Kubista, M. RT-qPCR workflow for single-cell data analysis. Methods 59, 80-88 (2013).

48. Kaelberer, M. M. \& Jordt, S. E. A method to target and isolate airway-innervating sensory neurons in mice. J. Vis. Exp. 2016, 1-7 (2016).

49. Stuart, T. et al. Comprehensive Integration of Single-Cell Data. Cell 177, 1888-1902.e21 (2019).

50. Kupari, J., Häring, M., Agirre, E., Castelo-Branco, G. \& Ernfors, P. An Atlas of Vagal Sensory Neurons and Their Molecular Specialization. Cell Rep. 27, 2508-2523.e4 (2019).

51. Lu, C. et al. Flexible and stretchable nanowire-coated fibers for optoelectronic probing of spinal cord circuits. Sci. Adv. 3, 1-8 (2017).

52. Su, Z., Alhadeff, A. L. \& Betley, J. N. Nutritive, Post-ingestive Signals Are the Primary Regulators of AgRP Neuron Activity. Cell Rep. 21, 2724-2736 (2017).

53. Sclafani, A. \& Ackroff, K. Flavor preferences conditioned by nutritive and non-nutritive sweeteners in mice. Physiol. Behav. 173, 188-199 (2017).

54. Domingos, A. I. et al. Leptin regulates the reward value of nutrient. Nat. Neurosci. 14, 1562-1568 (2011). 


\section{Acknowledgements}

The authors wish to thank Mr. Peter Weng, Ms. Marcia Montoya Gomez, Mr. Bradley Barth, Mr. Brayan Florentino, and Ms. Evie Freel for their contributions. We thank Mr. Carlton Anderson and Ms. Gabrielle Kelly in the CGIBD Advanced Analytics Core for assistance in single cell qPCR experiments. Our sincere appreciation is expressed to the staff of the Duke Light Microscopy Core, Flow Cytometry Core, and Department of Animal Research. Funding: HHMI Medical Research Fellowship to K.L.B., T32 DK007568 to M.M.K., Hartwell Postdoctoral Fellowship to L.R., F30 DK122712 to W.W.L, and DP2 MH122402, R21 AT010818, and Duke NUS Pilot Research Grant to D.V.B.

\section{Author Contributions}

K.L.B. optimized and performed flexible fiber implantation surgery and behavior experiments and performed all vagal cuff recordings, single cell qPCR experiments, optogenetic behavioral studies, and associated data analysis. L.E.R. optimized and performed pharmacologic and channelrhodopsin 2 behavior experiments. A.S., S.K., and P.A. designed and fabricated the flexible fiberoptic. M.M.K. performed all single cell calcium imaging, co-culture patch clamp electrophysiology experiments, and associated data analysis. M.E.K. cultured and maintained all organoids. M.E.K., K.L.B., and A.Y. optimized and performed glutamate release assays. K.L.B. and W.W.L. optimized the behavioral phenotyping system. W.W.L. analyzed single cell RNA sequencing data. J.V. planned and performed all animal breeding, mouse colony management, genotyping, and quality control. J.G. performed immunohistochemistry and quantification. K.L.B. and D.V.B. planned experiments and composed figures. D.V.B. conceptualized project, supervised the research, and wrote the final manuscript.

Competing interests: Some of the findings in this manuscript have been used to file a provisional patent application. D.V.B. is a member of the scientific advisory board of Holobiome Inc. on a fee-for-service basis. No other competing interests are declared.

Data and materials availability: All data is available in the manuscript, the supplementary materials, or upon request from the authors. 


\section{Extended Data}

Extended Data Video 1 | The illumenator. A conventional stiff, silica fiber (left) punctures an agar [1.5\%] membrane, but the flexible PC/PMMA fiber (right) does not.

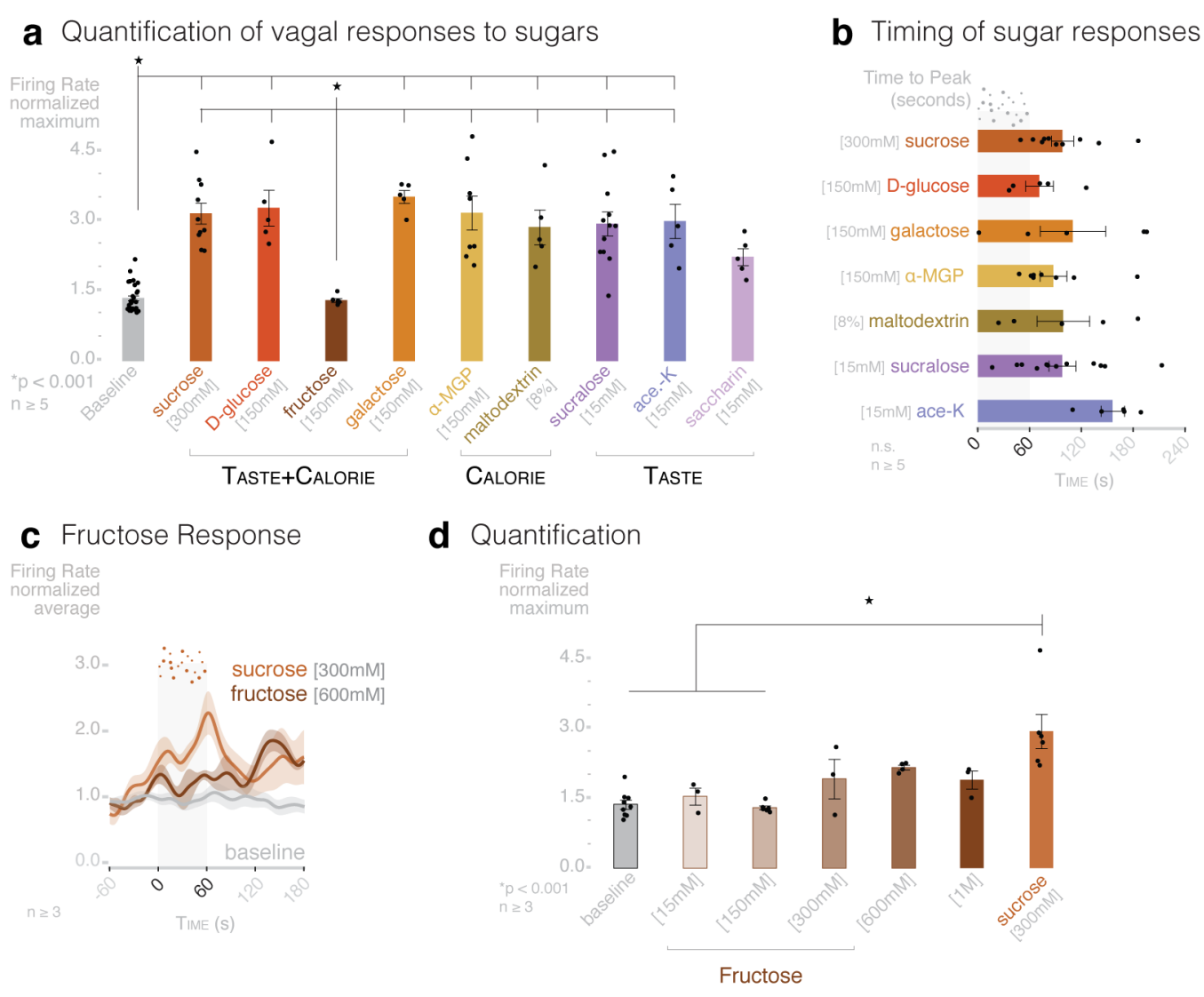

Extended Data Fig. $1 \mid$ Caloric and non-caloric sugars elicit a rapid vagal response. Additional data relating to Fig 1. a, Whole sugars (sucrose $[300 \mathrm{mM}]$, D-glucose $[150 \mathrm{mM}]$, fructose $[150 \mathrm{mM}]$, galactose $[150 \mathrm{mM}]$ ), non-sweet sugars (alpha-methylglucopyranoside ( $\alpha$-MGP) $[150 \mathrm{mM}]$, and maltodextrin $[8 \%]$ ), and non-caloric sugars (sucralose $[15 \mathrm{mM}]$, acesulfame $\mathrm{K}$ (ace-K) $[15 \mathrm{mM}]$, and saccharin $[15 \mathrm{mM}])$ were intraluminally delivered while recording vagal activity. All sugars elicited significant vagal firing compared to baseline except for fructose and saccharin in wild-type mice. ( $\mathrm{n} \geq 5$ mice per group; ${ }^{*} \mathrm{p}<0.001$, ANOVA with post hocTukey's HSD test). b, Time to peak vagal firing rate was similar across all stimuli that elicited a response $(\mathrm{n} \geq 5$ mice per group; $n$.s. by ANOVA with post hocTukey's HSD test). c, Normalized vagal traces for sucrose $[300 \mathrm{mM}]$, fructose $[600 \mathrm{mM}]$, and baseline in wildtype mice. d, High concentrations of fructose $(600 \mathrm{mM}, 1 \mathrm{M})$ elicit a blunted, but not significant, vagal response. ( $\mathrm{n} \geq$ 3 mice per group; statistics by ANOVA with post hocTukey's HSD test). Vertical bars indicate infusion period; all shaded regions and error bars represent SEM. 

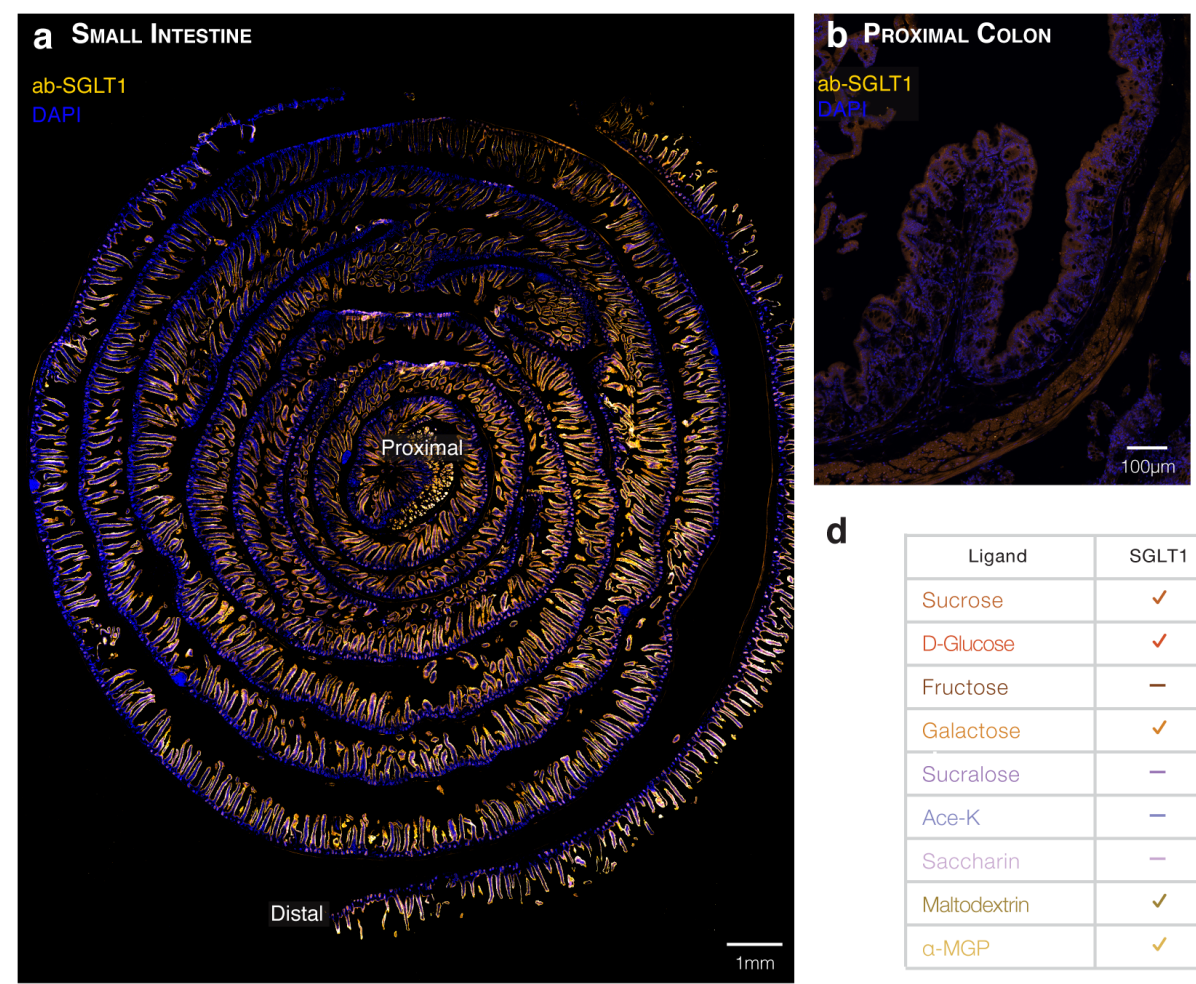

C Vagal response to sugar in colon

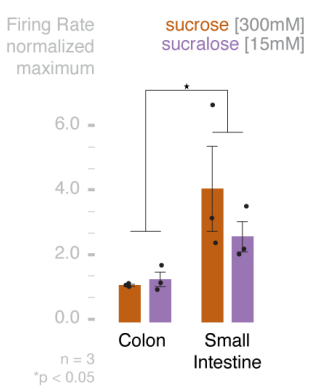

d

\begin{tabular}{|l|c|c|c|}
\hline \multicolumn{1}{|c|}{ Ligand } & SGLT1 & T1R2/3 & Met. \\
\hline Sucrose & $\checkmark$ & $\checkmark$ & $\checkmark$ \\
\hline D-Glucose & $\checkmark$ & $\checkmark$ & $\checkmark$ \\
\hline Fructose & - & $\checkmark$ & $\checkmark$ \\
\hline Galactose & $\checkmark$ & $\checkmark$ & $\checkmark$ \\
\hline Sucralose & - & $\checkmark$ & - \\
\hline Ace-K & - & $\checkmark$ & - \\
\hline Saccharin & - & $\checkmark$ & - \\
\hline Maltodextrin & $\checkmark$ & - & $\checkmark$ \\
\hline a-MGP & $\checkmark$ & $?$ & - \\
\hline
\end{tabular}

Extended Data Fig. 2 Intestinal SGLT1 is expressed consistently along the small intestine but minimally in the colon. a, A cross-section of the entire length of the small intestine shows consistent SGLT1 (yellow) expression across the length (proximal $=$ center). Scale $b a r=1 \mathrm{~mm}$. $\mathbf{b}$, Minimal SGLT1 expression is visualized in the proximal colon. Scale bar $=100 \mu \mathrm{m}$. c, Sucrose $[300 \mathrm{mM}]$ and sucralose $[15 \mathrm{mM}]$ infused intraluminally into the proximal colon do not elicit a vagal response ( $\mathrm{n} \geq 3$ mice per group; * $\mathrm{p}<0.05$, ANOVA with post hocTukey's HSD test; error bars indicate SEM). d, Caloric and non-caloric sugars act on different receptors (SGLT1 and T1R2/3) and are differentially metabolized (Met.). 
Calcium imaging of vagal neurons alone
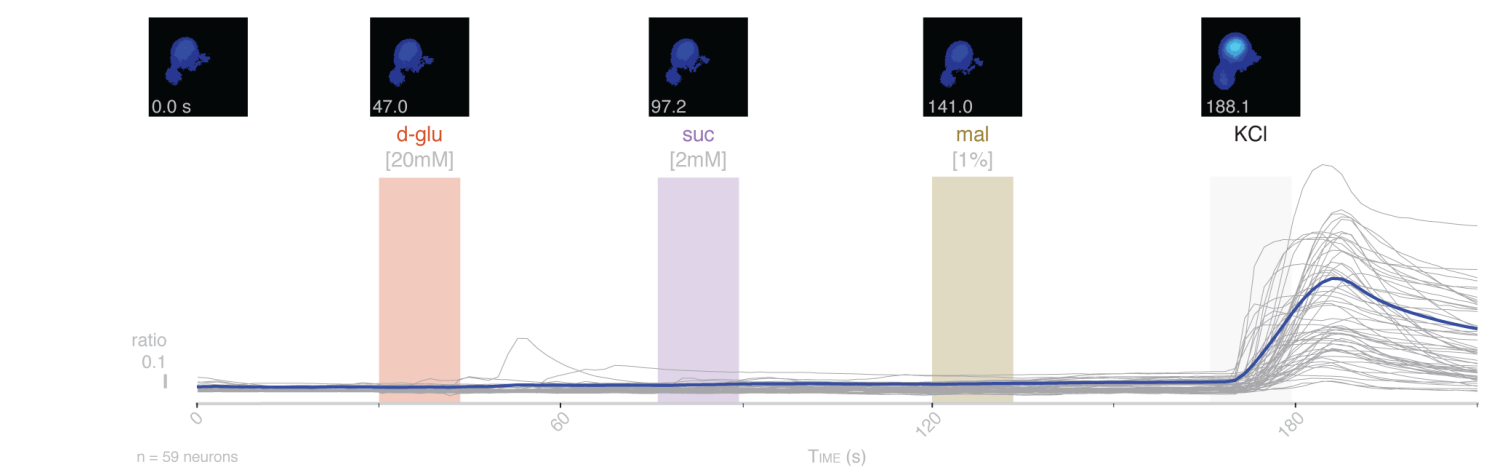

$\mathrm{KCl}$

b Single cell RNASeq of Nodose Neurons

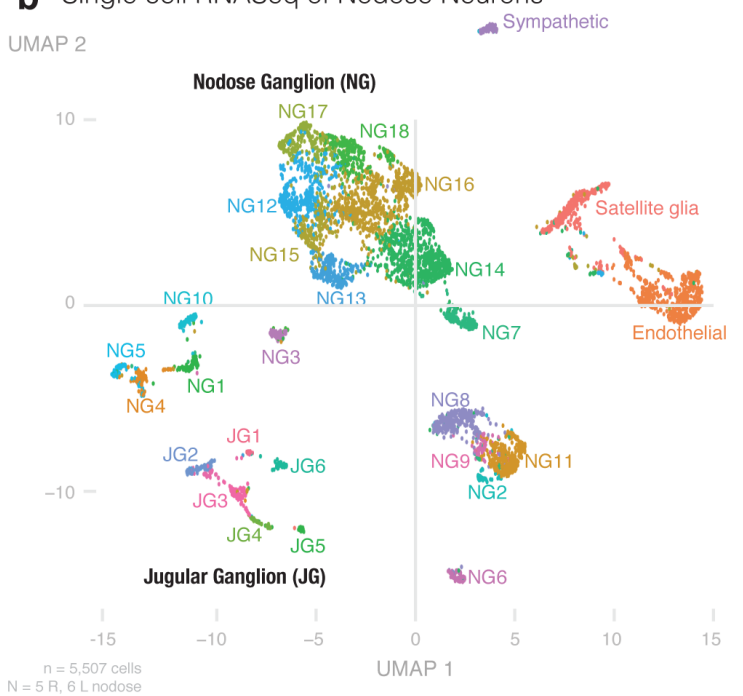

C Sugar receptors

d Co-culture EPSC

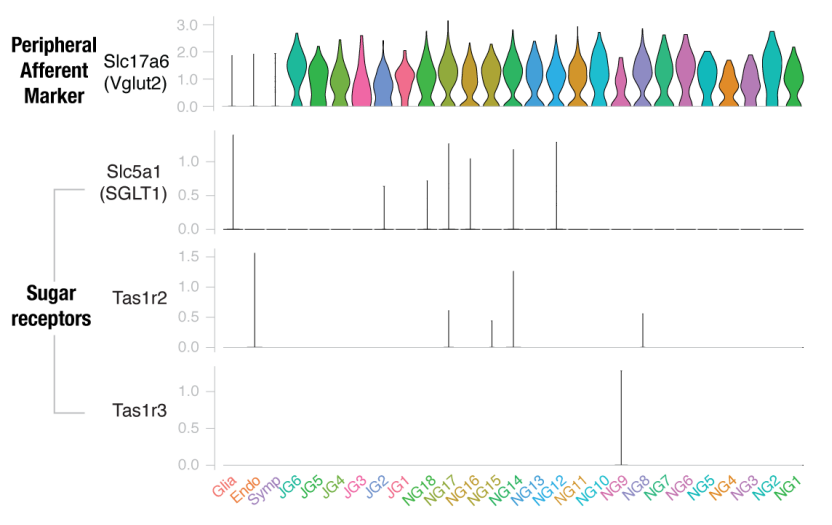

e Transmitter receptors
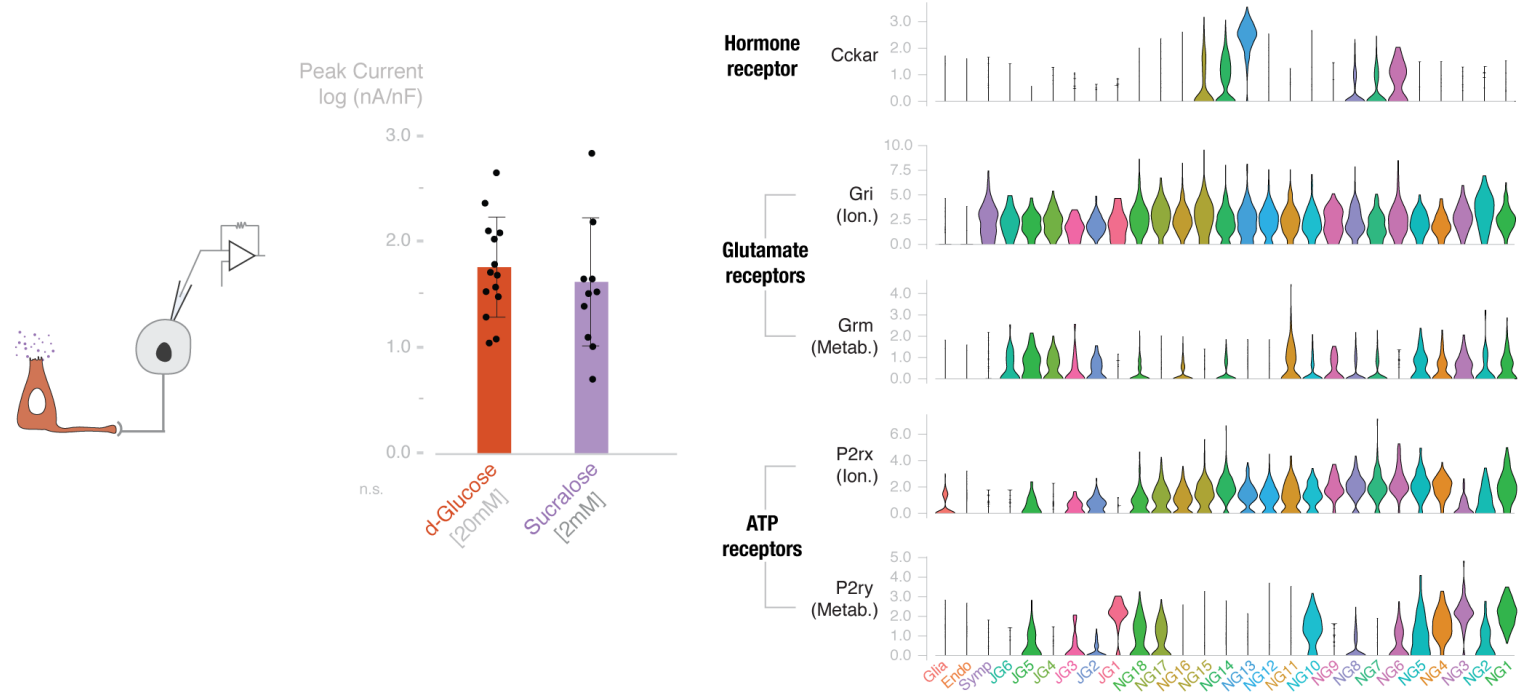

Extended Data Fig. 3 | Vagal nodose neurons have transcripts for both glutamatergic and purinergic neurotransmission. a, Vagal nodose neurons cultured alone do not respond to D-glucose [20mM], sucralose $[2 \mathrm{mM}]$, or maltodextrin $[1 \%]$ ( $\mathrm{n}=59$ neurons). $\mathbf{b}$, Single cell transcriptomic data projected onto the vagal nodose 
atlas showing 18 Nodose (NG) and 6 Jugular (JG) clusters. c, Violin plots showing transcripts for Slc5a1 (SGLT1), Tas $1 r 2$, and Tas $1 r 3$ are not expressed in vagal neurons. VGLUT2 (Slc17a6), a peripheral afferent marker, is found ubiquitously in nodose and jugular ganglion neurons. d, Additional data related to Figure $2 \mathrm{f}$. In co-culture patchclamp electrophysiology, the peak excitatory post-synaptic currents (EPSCs) elicited in connected nodose neurons was not significantly different between the application of D-glucose $[20 \mathrm{mM}]$ and sucralose $[2 \mathrm{mM}]$. ( $\mathrm{n}=18$ pairs). e, Several NG clusters (NG6-8, 13-5 ) show expression of Cckar transcripts. Ionotropic (Ion.) and metabotropic (Metab.) glutamatergic receptors and P2rx (ionotropic) and P2ry (metabotropic) purinergic receptors are also expressed in several NG and JG clusters. (for b, c, e: $\mathrm{n}=5,507$ cells; $\mathrm{N}=5$ right, and 6 left murine nodose ganglia). 
bioRxiv preprint doi: https://doi.org/10.1101/2020.03.06.981365; this version posted March 8, 2020. The copyright holder for this preprint (which was not certified by peer review) is the author/funder. All rights reserved. No reuse allowed without permission.

a Glutamate release in organoid culture

\begin{tabular}{|c|c|c|}
\hline \multirow[b]{2}{*}{ Ligand } & \multicolumn{2}{|c|}{$\begin{array}{l}\text { Glutamate Conc } \\
\text { in supernatant (ng } / \mu \mathrm{L})\end{array}$} \\
\hline & Mouse & Human \\
\hline PBS & $\begin{array}{r}2.632 \\
\pm 1.380\end{array}$ & $\begin{aligned} 4.253 \\
\pm 1.809\end{aligned}$ \\
\hline Sucrose & $\begin{aligned} & 13.46^{*} \\
\pm & 1.724\end{aligned}$ & $\begin{array}{l}23.44^{*} \\
\pm 8.998\end{array}$ \\
\hline a-MGP & $\begin{array}{l}18.18^{*} \\
\pm 7.904\end{array}$ & $\begin{array}{l}18.66^{*} \\
\pm 7.657\end{array}$ \\
\hline Sucralose & $\begin{array}{r}6.053 \\
\pm 1.169\end{array}$ & $\begin{aligned} & 2.508 \\
\pm & 1.157\end{aligned}$ \\
\hline
\end{tabular}

d Sweet taste alone is transduced by ATP

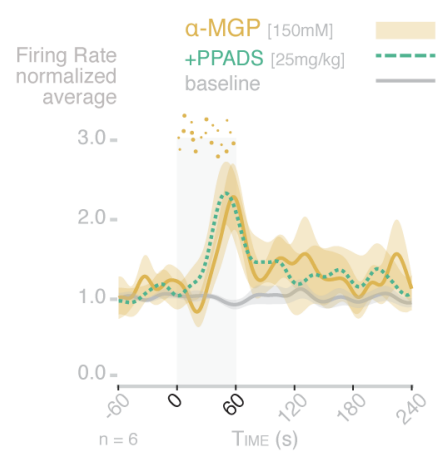

b Timing: Cck-AR inhibition

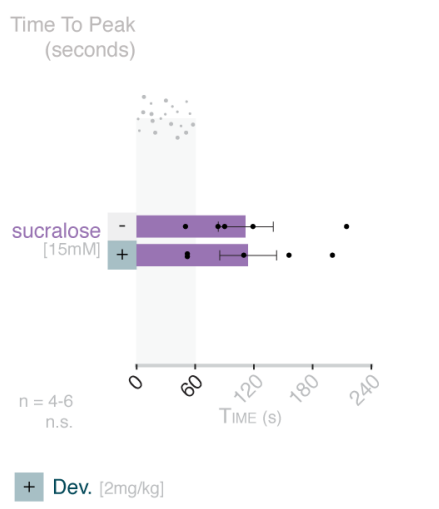

e Peak: P2 purinoreceptor inhibition

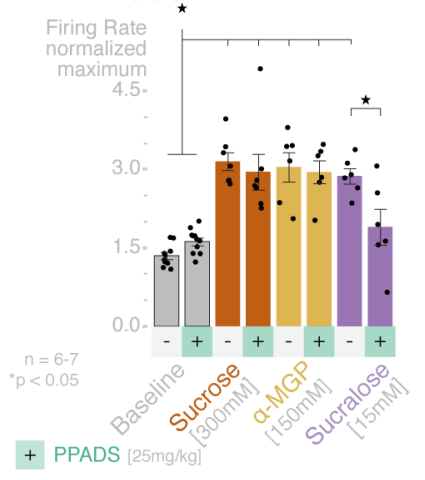

c Peak: Glu.R. inhibition

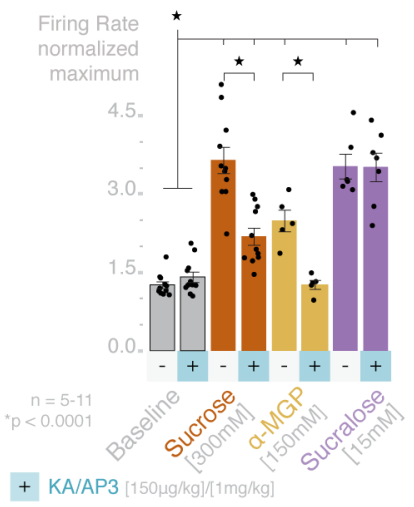

f Timing: P2 purinoreceptor inhibition

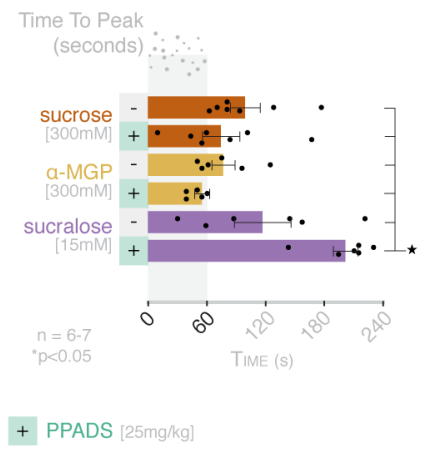

Extended Data Fig. $4 \mid$ Neuropod cells use different neurotransmitters to distinguish caloric sucrose from non-caloric sweeteners. a, Additional data related to Figure 3b. Quantification of glutamate concentration in supernatant for mouse and human organoids stimulated with PBS, sucrose $[300 \mathrm{mM}], \alpha \mathrm{MGP}[150 \mathrm{mM}]$, and sucralose [ $15 \mathrm{mM}$ ] (mouse: $\mathrm{n}=5-6$ plates, $\mathrm{N}=3$ mice, ${ }^{*} \mathrm{p}<0.05$ by Student's t-test compared to PBS; human: $\mathrm{n}=3-6$ plates, $\mathrm{N}=1$ human sample, ${ }^{*} \mathrm{p}<0.05$ by Student's t-test compared to PBS, sucralose). $\mathbf{b}$, Additional data related to Figure3c. Cck-A inhibition with devazepide (dev.; $2 \mathrm{mg} / \mathrm{kg}$ ) did not significantly change time to peak vagal firing rate in response to sucralose [15mM]. c-f, Additional data related to Figure3c-e. c, Quantification of peak vagal firing rate to sucrose $[300 \mathrm{mM}]$, sucralose $[15 \mathrm{mM}]$, and $\alpha \mathrm{MGP}[150 \mathrm{mM}]$ before $(-)$ and after $(+)$ inhibition with the glutamate receptor inhibitors kynurenic acid (KA) $[150 \mu \mathrm{g} / \mathrm{kg}]$ and AP3 $[1 \mathrm{mg} / \mathrm{kg}]\left(\mathrm{n}=5-11\right.$ mice, ${ }^{*} \mathrm{p}<0.0001$ ANOVA with post hoc Tukey's HSD test). d, Inhibition of non-selective P2 purinoceptors with PPADS [25mg/kg] did not attenuate the vagal response to $\alpha$ MGP $[150 \mathrm{mM}]$. e, Quantification of peak vagal firing rate to sucrose $[300 \mathrm{mM}]$, sucralose $[15 \mathrm{mM}]$, and $\alpha$ MGP $[150 \mathrm{mM}]$ before $(-)$ and after $(+)$ inhibition with PPADS $(\mathrm{n}=6-7$ mice, *p $<0.05$ ANOVA with post hoc Tukey's HSD test). f, Non-selective P2 purinoceptor inhibition with PPADS prolonged time to peak vagal firing rate to sucralose $[15 \mathrm{mM}]$ but not sucrose $[300 \mathrm{mM}]$ or $\alpha-M G P[150 \mathrm{mM}](\mathrm{n}=6-7$ mice, ${ }^{*} p<0.05$ ANOVA with post hoc Tukey's HSD test). Vertical bars indicate infusion period; all shaded regions and error bars represent SEM. 

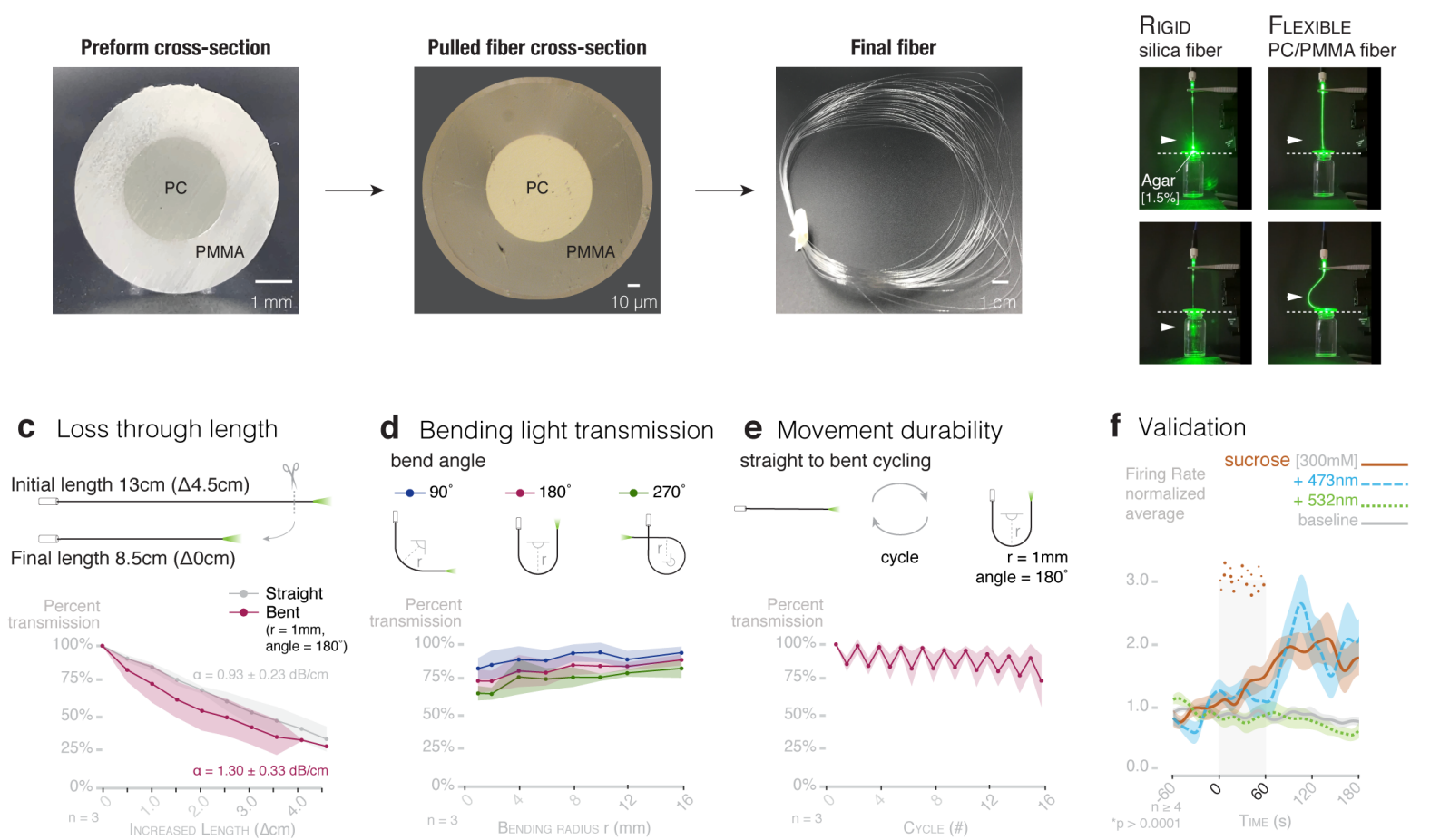

Extended Data 5 | The illumenator. a, Cross section images of PC/PMMA core/cladding preform, as-drawn PC/PMMA flexible fiber, and photograph of $\sim 50 \mathrm{~m}$ fiber bundle. $\mathbf{b}$, A novel flexible fiberoptic for gut intraluminal optogenetics in awake and behaving mice. A conventional rigid silica fiber punctures an agar $[1.5 \%]$ membrane, but the flexible fiber does not. c, Light transmission loss through the length of fiber. Light transmission for straight and bent (angle $=180^{\circ}$, radius of curvature $=1 \mathrm{~mm}$ ) flexible waveguides using the cut-back method. Percentage of light output from shortest length $(\Delta 0 \mathrm{~cm})$. Loss coefficients were calculated to be $0.93 \mathrm{~dB} / \mathrm{cm}$ and $1.30 \mathrm{~dB} / \mathrm{cm}$ for straight and bent fibers, respectively (shaded regions represent SD). d, Light transmission for fibers bent at angles $90^{\circ}, 180^{\circ}$, and $270^{\circ}$ for varied radii of curvature. Plotted as percentage of output from a straight fiber (shaded regions represent SD). e, Light transmission for flexible waveguides during cyclic bending at $180^{\circ}$ with a $1 \mathrm{~mm}$ radius of curvature (odd cycles $=$ straight, even $=$ bent). Plotted as percentage of output from initial position $($ cycle $=0)$ (shaded regions represent SD). f, Four weeks after implantation of the flexible fiberoptic in CckCRE_NpH3 mice, vagal recordings show its efficiency in silencing neuropod cells with $532 \mathrm{~nm}$, but not $473 \mathrm{~nm}$, laser. Vertical bar indicates infusion period; shaded regions represent SEM ( $\mathrm{n} \geq 4$ mice; * $\mathrm{p}<0.0001$ comparing maximum firing rate, ANOVA with posthoc Tukey's HSD test). 
a Activity during assay

CckCRE_Halo

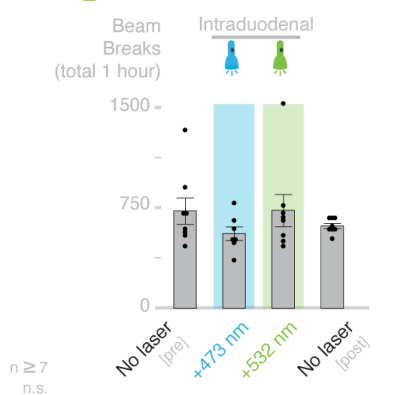

b 24

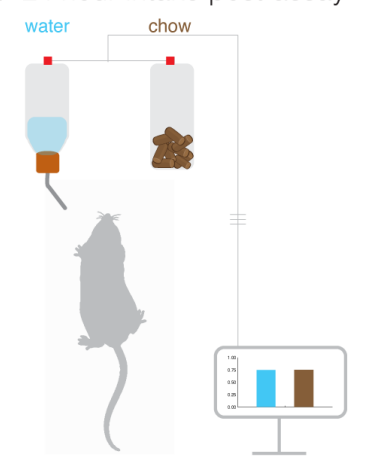

d Silencing laser in negative genotype littermate controls wild-type littermates

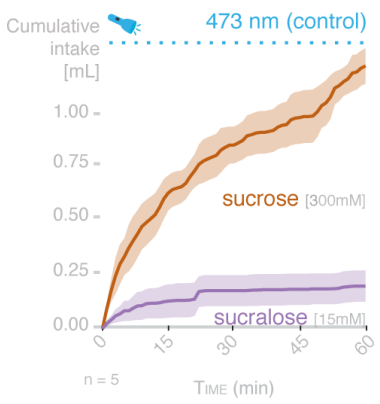

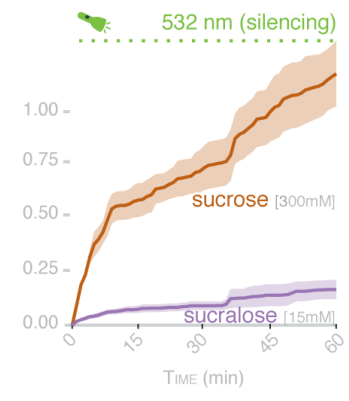

c Chow intake

CckCRE_Halo
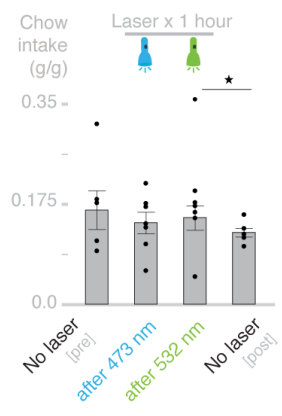

e Quantification

wild-type littermates
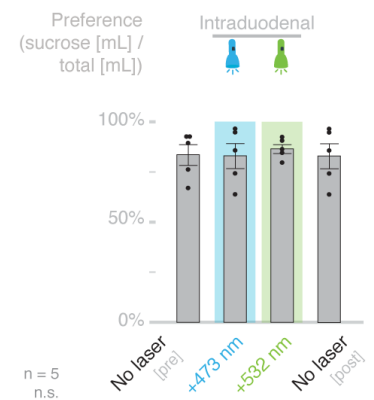

Water intake

CckCRE_Halo

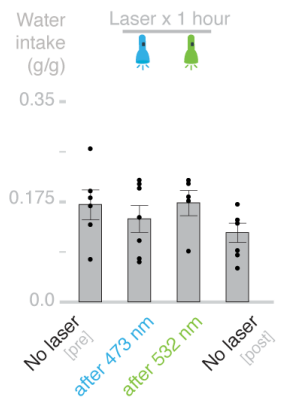

f Total intake wild-type littermates

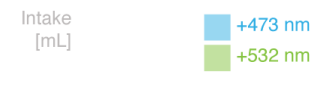

$2.0=$

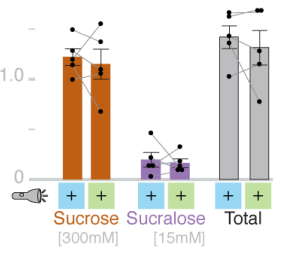

Extended Data Fig. 6 | Silencing neuropod cells does not cause malaise. a, Activity during assay is unchanged by 473nm (control) and 532nm (silencing) in Cck_Halo mice ( $\mathrm{n} \geq 7$, n.s. ( $>0.05)$ by repeated measures ANOVA). b, Water and chow consumption were measured during the 24 hours following the choice assay. During this time, mice moved freely and were not connected to laser. c, 532nm silencing laser applied for 1 hour during choice assay did not affect 24-hour intake of chow or water compared to $473 \mathrm{~nm}$ control laser applied for one hour during choice assay ( $\mathrm{n} \geq 6,{ }^{*} \mathrm{p}<0.01$ by repeated measures ANOVA with paired t-test post-hoc analysis). d, Average traces showing sucrose $[300 \mathrm{mM}]$ and sucralose $[15 \mathrm{mM}]$ consumption during $473 \mathrm{~nm}$ (control, left) laser and 532nm (silencing, right) laser inhibition in genotype-negative littermate controls of CckCRE_NpH3 mice. e, Preference for sucrose over sucralose is unchanged by $532 \mathrm{~nm}$ or $473 \mathrm{~nm}$ laser in genotype-negative littermate control mice. f, $532 \mathrm{~nm}$ or $473 \mathrm{~nm}$ does not affect sucrose, sucralose, or total intake in control mice $(\mathrm{n}=5$ littermate controls; $\mathrm{n} . \mathrm{s}$. $(\mathrm{p}>0.05)$ by repeated measures ANOVA). 

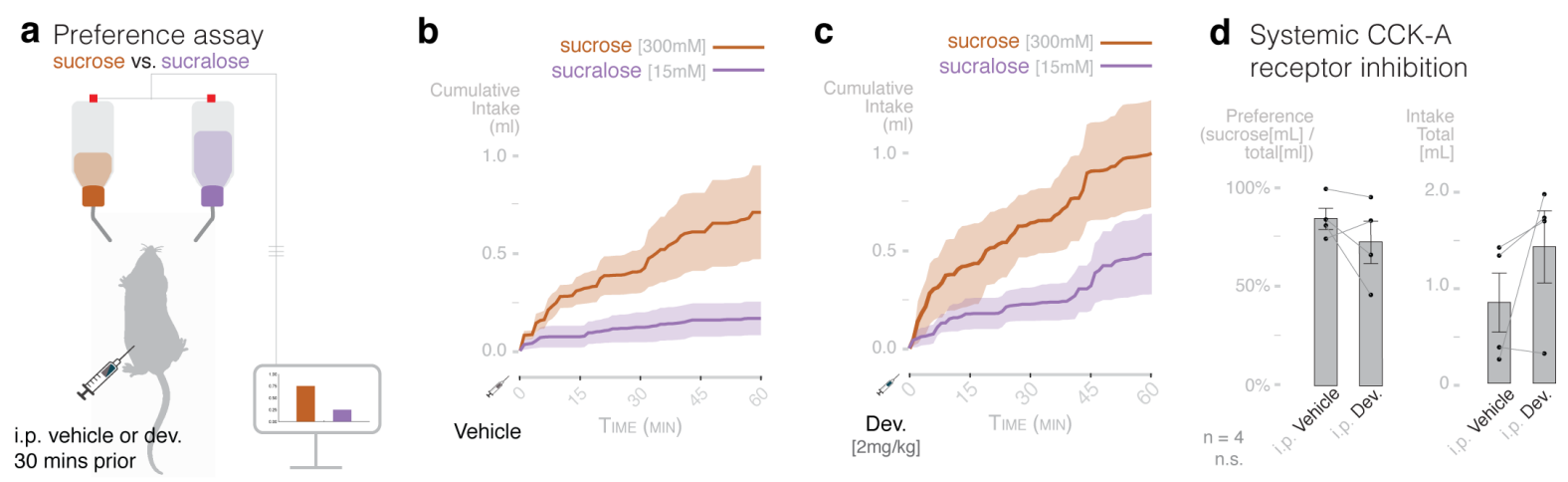

Extended Data Fig. $7 \mid$ Intraperitoneal cholecystokinin receptor inhibition does not eliminate preference for sucrose. a, Mice are given a two-bottle preference test between sucrose $[300 \mathrm{mM}]$ and sucralose $[15 \mathrm{mM}]$ for 1 hour. Drug or vehicle is administered intraperitoneal 30 minutes prior to assay. b-c, Average traces showing sucrose $[300 \mathrm{mM}]$ and sucralose $[15 \mathrm{mM}]$ consumption after intraperitoneal injection 30 minutes prior to solution access of $\mathbf{b}$, vehicle (PBS + 5\% DMSO) or c, CCK-A receptor inhibitor devazepide $([2 \mathrm{mg} / \mathrm{kg}]$ in $10 \mu \mathrm{L} / \mathrm{g}$ mouse in $5 \%$ DMSO in PBS) in wild-type mice. d, Preference for sucrose over sucralose is unchanged by devazepide compared to vehicle in wild-type mice ( $n=4$, n.s. $\mathrm{p}=0.6257$ on repeated measures ANOVA). Total intake trends toward increasing with Cck-A receptor inhibition compared to vehicle control $(n=4$, n.s. $p=0.2353$ on repeated measures ANOVA). 
a One-bottle assay

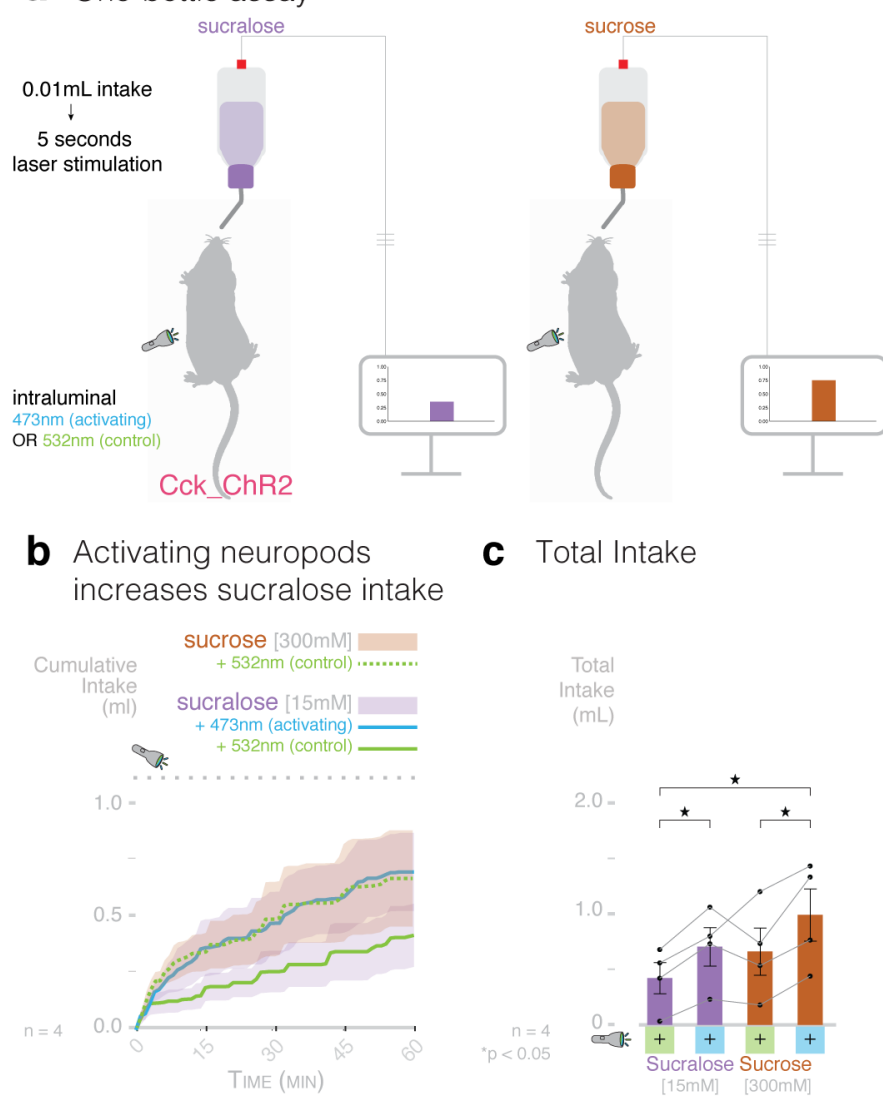

Extended Data Fig. 8 | Optogenetic stimulation of neuropod cells increases consumption of caloric and noncaloric sugars in a one-bottle test. a, Design:

CckCRE_Channelrhodopsin (Cck_ChR2) mice are given a one-bottle intake test of sucrose $[300 \mathrm{mM}]$ or sucralose [ $15 \mathrm{mM}]$ for 1 hour with $532 \mathrm{~nm}$ (control) or $473 \mathrm{~nm}$ (activating) laser. Laser stimulation is paired to solution consumption: for every $0.01 \mathrm{~mL}$ intake, mice receive 5 seconds of intraluminal stimulation at $40 \mathrm{~Hz}$. Solution*laser conditions were counter-balanced to control for order effect. $\mathbf{b}$, Average traces showing consumption of sucrose $[300 \mathrm{mM}]+532 \mathrm{~nm}$ control laser, sucralose $[15 \mathrm{mM}]+473 \mathrm{~nm}$ activating laser, and sucralose $[15 \mathrm{mM}]+532 \mathrm{~nm}$ control laser in Cck_Chr2 mice. c, Stimulation of duodenal neuropod cells with $473 \mathrm{~nm}$ increases consumption of both sucrose $[300 \mathrm{mM}]$ and sucralose $[15 \mathrm{mM}]$. Neuropod activation with $473 \mathrm{~nm}$ increases consumption of sucralose to consumption of sucrose with control laser $(n=4$; ${ }^{*} \mathrm{p}<0.05$, repeated-measures ANOVA with post-hoc paired ttest). Shaded regions or error bars indicate SEM. 


\section{Methods}

Mouse strains. All experiments on mice were performed following approval by the Institutional Animal Care and Use Committee at Duke University Medical Center under the protocol A28018-12. Mice were group housed in Duke University's Division of Laboratory Animal Resources, where they were kept on a 12-hour light-dark cycle (0700-1900) with access to water and standard mouse chow (Purina 5001) ad-libitum, unless otherwise indicated. Male and female adult mice aged 4-20 weeks were used in all experiments. The mouse strains, source, background, and stock number used to breed experimental mice are listed in the table below. The following experimental mouse strains were purchased/received/bred in-house and used directly: C57B16/J, Swiss Webster, and CckGFP. The following double transgenic mouse strains were bred in-house: CckCRE_tdTomato, CckCRE_Halo-YFP, and CckCRE_ChR2-tdTomato.

\begin{tabular}{|l|l|l|l|}
\hline Mouse genotype & Source & Background & Stock Number \\
\hline Wild type & Jackson Lab & C57BL/6J & 000664 \\
\hline Wild type & Charles River & Swiss Webster & 024 \\
\hline CckGFP & $\begin{array}{l}\text { Courtesy of Liddle } \\
\text { Laboratory }\end{array}$ & Swiss Webster & Wang et al., (2010) 35 \\
\hline CckCRE & Jackson Lab & C57BL/6J & 012706 \\
\hline LSL_tdTomato & Jackson Lab & C57BL/6J & 007914 \\
\hline LSL_Halo-YFP & Jackson Lab & C57BL/6J & 014539 \\
\hline LSL_ChR2-tdTomato & Jackson Lab & C57BL/6J & 012567 \\
\hline
\end{tabular}

$*$ LSL $=$ loxP-STOP-loxP cassette

Human samples. Human duodenal samples were obtained from the Duke University Medical Center Biorepository and Precision Pathology Center (BRPC) under the Institutional Review Board (IRB) protocol Pro00035974 via anonymous tissue release. All samples were deidentified and all links to additional patient information were broken prior to receipt of fresh surgical specimens. Following surgical extraction, samples were placed in sterile PBS and stored at $4^{\circ} \mathrm{C}$ prior to crypt dissociation.

Organoid culture. Murine organoids. Mouse organoids were cultured from CckGFP mice ( $\mathrm{n}=$ 3) per Sato et al. (2009). ${ }^{36}$ Briefly, the proximal one third of the small intestine was flushed with cold PBS, opened lengthwise and cut into $\sim 1 \mathrm{~cm}$ pieces. Tissue pieces were incubated with 1.5mM EDTA on ice for 25 minutes then $37{ }^{\circ} \mathrm{C}$ for 15 minutes. Crypts were detached by shaking in cold PBS, pelleted at 100xg and resuspended in Matrigel (Corning \#356231). Crypts were plated in $50 \mu 1$ mounds in 24 well plates and maintained in organoid culture media containing $1 \mathrm{x}$ Glutamax (Gibco), 10mM HEPES (Gibco), 200U/ml Penicillin-Streptomycin (Gibco), 1x N2 supplement (Gibco), 1x B27 supplement (Gibco), 1mM N-acetylcysteine (Sigma), 50ng/ml EGF (Peprotech), 100ng/ml Noggin (Peprotech), and 10\% R-spondin conditioned media (produced in 
house using Trevigen 3710-001-K cells) in Advanced DMEM/f12 (Gibco). 10 $\mu \mathrm{M}$ Y-27632 (Enzo) was added to the culture media for initial plating.

Human organoids. Human organoids were cultured per Fujii et al. (2015). ${ }^{30}$ Human tissue was washed in PBS and the epithelial layer was dissected from submucosa and connective tissue and minced. All tips and tubes used were coated with FBS. Tissue pieces were washed in PBS until washes were clear then incubated in 5mM EDTA in PBS for 1 hour, on ice. Crypts were detached by shaking in cold PBS, pelleted at 100xg and resuspended in Matrigel (Corning \#356231). Crypts were plated in 50 $\mu 1$ mounds in 24 well plates and maintained in Human Intesticult (Stem Cell \#06010) with 10 $\mu$ M Y-27632 at initial plating.

Glutamate release assay. Murine or human small intestinal organoids were passaged and plated into a 96 well plate in $25 \mu \mathrm{L}$ Matrigel mounds in organoid culture media as above. The human organoid media contained 500ng/ml human r-spondin (Peprotech) and was supplemented with 500nM A-83-01 (Tocris) and 10nM leu-gastrin (Sigma) for differentiation with 10 $\mu \mathrm{M} \mathrm{Y-27632}$ at passage. ${ }^{37}$ When mature morphology was achieved 3-7 days after passage, media was removed and organoids were washed in PBS twice for 5 minutes at RT. Organoids were then stimulated with $60 \mu \mathrm{L}$ of $300 \mathrm{mM}$ sucrose, $150 \mathrm{mM}$ alpha-methylglucopyranoside ( $\alpha$-MGP), $15 \mathrm{mM}$ sucralose, or PBS for 10 minutes at $37^{\circ} \mathrm{C}$. Supernatant was collected, centrifuged for 10 minutes at $13,000 \mathrm{xg}$ to remove insoluble material, and stored at $-20^{\circ} \mathrm{C}$ for up to 2 weeks. Glutamate concentration in samples was assessed using the Glutamate Release Assay Kit (Sigma). $30 \mu \mathrm{L}$ of each sample was mixed with buffer, glutamate enzyme mix, and developer following manufacturer's protocol. Each experimental condition was run in triplicate on every plate. A glutamate standard was run for every plate. Control wells of sample and developer without enzyme mix were run in duplicate and included for each sample. 450nm absorbance was measured on a plate reader (Tecan Infinite 200 Pro). Nine reads were taken per well and averaged. The absorbance from the control was subtracted from each experimental sample absorbance for the corrected value. Glutamate amount and concentration was calculated using the standard curve.

Vagus nerve recordings. Whole nerve recordings were performed in wild-type mice $(\mathrm{n}=5-11$ per group), CckCRE_Halo-YFP mice ( $n=5$ per group), and CckCRE_Halo-YFP mice following fiberoptic implantation ( $n=4-5$ per group). Whole nerve electrophysiology recordings of the cervical vagus nerve were performed as previously reported. ${ }^{10}$ A 20 -gauge gavage needle with two connected tubes for PBS perfusion and stimulant delivery was surgically inserted through the stomach wall into the duodenum (for small intestine experiments) or the proximal colon distal to the cecum (for colon experiments). A perfusion exit incision was made at the ligament of treitz for the small intestine or just proximal to the rectum for colon. PBS was constantly perfused through the isolated intestinal region at $\sim 400 \mu \mathrm{L}$ per minute as a baseline and volume pressure control. Stimulation conditions were applied after recording 2 minutes of baseline activity. During nutrient stimulation conditions, PBS perfusion was continuous and $200 \mu \mathrm{L}$ of stimulant was perfused over 1 minute using a syringe pump (Fusion 200, Chemyx). All caloric and non-caloric sugar ligands were purchased from Sigma and dissolved in PBS. The final concentration for each infused nutrient is as follows: $8 \%$ maltodextrin, $150 \mathrm{mM}$ alphamethylglucopyranoside ( $\alpha$-MGP), $15 \mathrm{mM}$ sucralose, $15 \mathrm{mM}$ acesulfame $\mathrm{K}$ (ace-K), $15 \mathrm{mM}$ 
saccharin, $300 \mathrm{mM}$ sucrose, $150 \mathrm{mM}$ d-glucose, $150 \mathrm{mM}$ galactose, $15 \mathrm{mM}-1 \mathrm{M}$ fructose. All sugar ligands were purchased from Sigma.

Data Acquisition. Extracellular voltage was recorded as previously described. ${ }^{10}$ The raw data was analyzed using Spike Tailor, a custom MATLAB software (Mathworks) script. ${ }^{10}$ Spikes were detected using a threshold detected based on RMS noise. The firing rate was calculated using a Gaussian kernel smoothing algorithm in 200-ms bins. ${ }^{38}$

Optogenetic inhibition. A standard stiff silica fiber optic cable (FT020, ThorLabs) was threaded through or along the gavage needle into the duodenal lumen. Laser stimulation was applied simultaneously with nutrient infusion. The laser was pulsed for 1 minute at $40 \mathrm{~Hz}, 5 \mathrm{~V}$ peak, and $20 \%$ duty cycle $(473 \mathrm{~nm}, 80 \mathrm{~mW}$ laser, RGBlase; $532 \mathrm{~nm}, 80 \mathrm{~mW}$ laser, RBGlase).

SGLT1/T1R2/3 inhibition. For apical receptor inhibition, the SGLT1 competitive inhibitor phloridzin dihydrate (Sigma) or the sweet taste receptor inhibitor (T1R2/3) gurmarin (Peptides International) were dissolved into $1 \mathrm{M}$ sucrose, $45 \mathrm{mM}$ sucralose, or $450 \mathrm{mM} \alpha$-MGP. Following recording of a pre-inhibitor response to the selected ligand, sucrose, sucralose, or $\alpha$-MGP were perfused with the apical receptor inhibitors, for a final phloridzin concentration of $3 \mathrm{mM}^{10}$ and a final gurmarin concentration of $7 \mu \mathrm{M} \cdot{ }^{39,40}$ Each mouse received one only inhibitor.

Neurotransmitter inhibition. The following neurotransmitter/neuropeptide blockers were used: CCK-A receptor antagonist devazepide ([2mg/kg] in 5\% DMSO PBS; Sigma $)^{10,41}$; cocktail of the ionotropic glutamate receptor antagonist kynurenic acid (KA) $([150 \mu \mathrm{g} / \mathrm{kg}]$ in PBS, stock made in $1 \mathrm{M} \mathrm{NaOH}$ then diluted, $\mathrm{pH} 7.4$; Sigma $)^{10,42}$ and the metabotropic glutamate receptor antagonist DL-2-Amino-3-phosphonopropionic acid (AP-3) $([1 \mathrm{mg} / \mathrm{kg}]$ in PBS, stock made in $1 \mathrm{M} \mathrm{NaOH}$ diluted, $\mathrm{pH}$ 7.4; Sigma) ${ }^{10,43}$; and non-selective P2-purinoreceptor antagonist pyridoxalphosphate-6-azophenyl-2',4'-disulfonic acid (PPADs) ([25mg/kg] in PBS; Sigma). ${ }^{27,44-}$ ${ }^{46}$ Following recording of a pre-inhibitor response, one inhibitor was delivered over one minute (devazepide and PPADS were delivered $10 \mu \mathrm{L} / \mathrm{g}$; KA/AP3 cocktail was delivered $20 \mu \mathrm{L} / \mathrm{g}$ ). For devazepide, infusion of the selected sugar ligand was repeated for post-inhibitor recording after a 5-8 minute incubation period. For KA/AP3 and PPADs, infusion of the selected sugar ligand was repeated for a post-inhibitor recording after a 3-5 minute incubation period.

Data Analysis. Stimulation response was quantified as the maximum firing rate after stimulation (stimulant conditions) or during recording (baseline). Time to peak was also quantified as the time from the start of infusion to the maximum firing rate for stimulant conditions which evoked vagal firing. Each trial served as its own control by normalizing the firing rate to the pre-stimulus baseline firing rate (first 2 minutes of recording). Throughout experiments, sucrose response was used as a positive control. For all nutrient and laser stimulation conditions, data were excluded if a sucrose response was not seen throughout the recording session. Maximum firing rate, time to peak, and area under the curve were analyzed across stimulation condition.

Immunohistochemistry. CckGFP $(\mathrm{n}=3)$ mice were transcardially perfused with PBS for 3 minutes followed by $4 \%$ PFA for 3 minutes at a rate of $600 \mu 1 / \mathrm{min}$. Each small intestine was harvested, opened lengthwise, rolled with the proximal end in the center, and post-fixed in $4 \%$ PFA for 3 hours. Tissue was then dehydrated in 10\% sucrose for 1 hour and $30 \%$ sucrose for at 
least 12 hours. Samples were embedded in OCT (VWR) and stored at $-80^{\circ} \mathrm{C}$. Tissue was sectioned onto slides at $14 \mu \mathrm{m}$ using a cryostat. Tissue slides were post-fixed in $10 \%$ normal buffered formalin (VWR) for 10 minutes then washed in tris-buffered saline with $0.05 \%$ Tween20 (TBST) (Sigma). SGLT1 staining was achieved by performing heat mediated antigen retrieval. Trisodium citrate dihydrate buffer $(10 \mathrm{mM}$ in PBS, $0.05 \%$ Tween, $\mathrm{pH} 6.0$; Sigma) was heated in a slide holder in a water bath to $>90^{\circ} \mathrm{C}$. Tissue slides were immersed for 20 minutes and then immediately placed into cool tap water then washed in TBST for 5 minutes. Tissue was blocked in 10\% donkey serum (Jackson ImmunoResearch) for one hour. Tissue was then incubated with primary antibody dissolved in antibody dilution solution (PBS with 1\% BSA and $0.0025 \%$ Triton-X 100) for 24 hours at $4{ }^{\circ} \mathrm{C}$ then one hour at room temperature. Primary antibodies and dilutions were as follows: Rb-Anti-SGLT1 (1:100; Abcam: ab14686) and ChkAnti-GFP (1:500; Abcam: ab13970). Following primary antibody incubation, tissue was washed in TBST then incubated with secondary antibody in antibody dilution solution for 1 hour at room temperature (Jackson ImmunoReseach: Dk-Anti-Rb-488 (1:250); Dk-Anti-Rb-Cy3 (1:250); DkAnti-Ck-488 (1:250)). Tissue was then washed with TBST, stained with DAPI (1:4000) for 3 minutes, washed in TBST, and mounted using Fluoro-Gel with Tris Buffer (Electron Microscopy Sciences). Imaging was done on a Zeiss 880 Airyscan inverted confocal microscope. Images were adjusted for brightness/contrast using ImageJ (Fiji). Counts are presented as the mean percentage of co-localization \pm SEM.

Dissociation and isolation of single intestinal epithelial cells. Small intestines of mice were dissociated for single cell quantitative PCR (CckGFP; $n=3)$, calcium imaging (CckCRE_tdTomato; $n=8)$, or in vitro electrophysiology (CckCRE_tdTomato; $n=9$ ) as previously described. ${ }^{10}$ Briefly, the proximal half of the small intestine was removed, flushed with cold PBS, and cut into sections. Tissue was shaken in 3mM EDTA in PBS for 15 minutes at $4{ }^{\circ} \mathrm{C}$ followed by a 15 -minute incubation at $37^{\circ} \mathrm{C}$. The epithelial layer was then mechanically detached from the muscle layer by shaking in cold PBS. Following centrifugation at 800rpm (Eppendorf $5702 \mathrm{RH}$; rotor A-4-38), the pellet was resuspended and incubated in HBSS (Gibco) with dispase and collagenase for 10 minutes at $37^{\circ} \mathrm{C}$. Sample were then centrifuged $(500 \mathrm{rpm})$, filtered twice through a $70-\mu \mathrm{m}$ and $40-\mu \mathrm{m}$ filter, and resuspended in L15 media (5\% FBS, $10 \mu \mathrm{L} / \mathrm{mL} 10 \mathrm{mM}$ HEPES, $2000 \mathrm{U} / \mathrm{mL}$ Pen-Strep, and $100 \mu \mathrm{L}$ of $1700 \mathrm{U} / \mathrm{mL}$ DNAse) to produce single cell suspension for further analysis.

Single cell quantitative PCR (qPCR). RNA isolation from single cells was performed using the Cells Direct One-Step qRT-PCR Kit (CDK kit, ThermoFisher) per manufacturer's protocol. $5 \mu \mathrm{L}$ Lysis Buffer Mix was pipetted into each well of a 96-well plate and spun down at 500g to spread buffer. Following dissociation protocol, single cells were sorted into a U-bottom 96 well plate (Sigma) based on GFP signal using a MoFlo XDP sorter. For each mouse, 60 GFP positive cells, 30 GFP negative cells, and control wells were sorted. Control wells of 0, 10, and 100 cells were run in duplicate. Following sort, the contents of each well were pipetted into a 96-tube $0.2 \mathrm{~mL}$ PCR plate which was then incubated in a thermocycler at $75^{\circ} \mathrm{C}$ for 10 minutes. After spinning to pellet, DNAase I and 10x DNAase I reaction buffer from the CDK kit were added to each well and incubated at $25^{\circ} \mathrm{C}$ for 5 minutes. $2 \mu \mathrm{L}$ of $25 \mathrm{mM}$ EDTA was added to each well, vortexed, and pelleted. The plate was then incubated at $75^{\circ} \mathrm{C}$ for 10 minutes to inactivate the DNAase I. Next, cDNA was synthesized and pre-amplified. Specific Target Amplification (STA) mix was made by mixing $1 \mu \mathrm{L}$ of each TaqMan probe. STA mix, superscript $\mathrm{RT}$, and reaction buffer from the 
CDK kit were added to each sample and incubated on a thermocycler for 15 minutes at $50^{\circ} \mathrm{C}, 2$ minutes at $95^{\circ} \mathrm{C}$, then 20 cycles of 15 seconds at $95^{\circ} \mathrm{C}$ and 4 minutes at $60^{\circ} \mathrm{C}$. Gene expression was then probed using the 96.96 Dynamic Array integrated fluidic circuit on a Biomark using manufacturer protocol (Fluidigm).

Quality control. Quality of the Ct values from the Biomark output was assessed using the Fluidigm Real-Time PCR Analysis software (Fluidigm). All trials ( $\mathrm{N}=3$ mice, $\mathrm{n}=60$ positive cells and 30 negative cells per mouse) were loaded simultaneously for analysis. The quality was analyzed in linear derivative mode and the quality threshold was set at 0.65 based on manufacturer's recommendations. All curves not meeting the quality threshold were analyzed visually for smoothness (more smooth representing high quality) and entered into analysis based on comparison with passing curves. All cells not meeting quality measures or having no detected transcripts for either housekeeping gene (Gapdh or Actb1) were excluded from analysis (48 positive cells, 24 negative cells were excluded).

Analysis. Further processing of Ct values was performed based on Stahlberg (2012). ${ }^{47}$ Relative quantities of cDNA molecules (RQ) were calculated using the formula $R Q=2^{\wedge}\left(\mathrm{Cq}_{\text {cutoff }}-\mathrm{Cq}\right)$ using a $\mathrm{Cq}_{\text {cutoff }}$ value of 34 . The RQ value for any sample expressing no detectable transcripts for a gene was set at 0.5 . All data was expressed in a log2-scale. Heat maps were generated for gene expression normalized within each gene using Qlucore Omics Explorer (Qlucore). Differential gene expression analysis (between 1) CckGFP+ and CckGFP- and 2) CckGFP+Slc5al+ and CckGFP+Slc5al-) was carried out using two-group t-test comparisons with a q-value cut-off of 0.01 (Qlucore).

Calcium imaging. For neurons, C57BL/6J $(n=3)$ nodose neurons were dissociated and plated as previously described. ${ }^{48}$ Briefly, nodose ganglia were dissected and immediately placed into 500 $\mu \mathrm{L}$ of ganglia dissociation solution containing $10 \mathrm{mM}$ HEPES, 1x Glutamine, 1x N2 supplement, 1x B27 supplement, $0.5 \mu \mathrm{g} / \mathrm{mL}$ NGF, and $55 \mu \mathrm{g} / \mathrm{mL}$ of Liberase (Roche, 5401054001) in Advanced DMEM/f12. Following digestion, ganglia were rinsed twice with PBS, mechanically dissociated in dissociation solution, and filtered through a $70 \mu \mathrm{m}$ cell strainer. They were then plated on $12 \mathrm{~mm}$ coverslips and placed in a $37^{\circ} \mathrm{C}$ incubator overnight. Cells were imaged 1-2 days after plating. For enteroendocrine cells, CckCRE_tdTomato $(n=8)$ cells were dissociated as described in the dissociation section and fluorescence sorted (BD FACSAria) selecting for tdTomato+ fluorescent cells. Cells were then plated on coverslips coated with $2.5 \%$ Matrigel (Corning \#356231). Enteroendocrine cells were imaged 2-6 hours after plating. To load cells with calcium dye, cells were washed once with calcium free PBS then incubated for 45 minutes at $37^{\circ} \mathrm{C}$ with $5 \mu \mathrm{M}$ Fluo-4, AM and $5 \mu \mathrm{M}$ Fura Red, AM calcium dyes (Life Technologies, Carlsbad, CA) and 0.1\%Pluronic F-127 (Life Technologies) in imaging buffer (120mM NaCl, $3 \mathrm{mM} \mathrm{KCl}, 2 \mathrm{mM} \mathrm{CaCl}_{2}, 2 \mathrm{mM} \mathrm{MgCl} 2,10 \mathrm{mM}$ HEPES, $10 \mathrm{mM}$ glucose). The loading buffer was then removed, and cells were washed twice with imaging buffer and placed in the dark for 15 minutes until they reached room temperature. Coverslips were then placed in the recording chamber of a Zeiss Examiner Z1 and imaged with a Hamamatsu camera (Orca-flash4.0; C11440) using the Zeiss ZEN Blue software package. Fluo-4 and Fura red emission images were obtained using 480-nm and 570-nm excitation, respectively. Images were collected at 1.5 second intervals with a $100 \mathrm{~ms}$ exposure time. Each recording was 210 seconds (3.5 minutes) long. Imaging buffer was continuously perfused $(\sim 2 \mathrm{ml} / \mathrm{min})$ over the coverslips throughout the imaging 
session. Four stimuli were applied during each recording: $20 \mathrm{mM}$ d-glucose, $2 \mathrm{mM}$ sucralose, $1 \%$ maltodextrin, and $50 \mathrm{mM} \mathrm{KCl}$ (at the end as an activity control). Stimuli were each delivered for 15 seconds at 30,75, 120, and 165 seconds following the start of the recording. Following each 15 second stimulus delivery, imaging buffer was perfused to wash away the stimulus. The order of the three experimental stimuli was counterbalanced to offset any potential order effects. Each recording session concluded with the $50 \mathrm{mM} \mathrm{KCl}$ activity control.

Analysis: Fluorescence values for each individual cell were calculated as the mean fluorescence intensity in a user-defined region of interest on Fiji software. Intracellular calcium changes were then calculated as $\Delta \mathrm{F} / \mathrm{R}(\Delta \mathrm{F}=$ change in fluorescence of the ratio, $\mathrm{R} ; \mathrm{R}=$ fluo-4/fura red $)$ based on baseline fluorescence. Ratiometric values were then normalized to the peak $\mathrm{KCl}$ response. A positive response was defined as an increase in ratio $>10 \%$ above baseline. Student's paired t-test was used for a single comparison between stimuli and KCl. Significance was set at $\mathrm{p}<0.05$. Statistical analyses were carried out using MATLAB software (Mathworks) and graphs were made with MS Excel.

Neuropod cell and vagal nodose neuron co-culture. The small intestines of CckCRE_tdTomato mice were dissociated to single cell as described in the dissociation section. Cells were sorted using fluorescence activated cell sorting (BD FACSAria) selecting for tdTomato+ fluorescent cells. Cells were sorted into co-culture media (1x Glutamax, $1010 \mathrm{mM}$ HEPES, 200U/ml Penicillin-Streptomycin, 1x N2 supplement, 1x B27 supplement, 10ng/ml NGF, $0.25 \mathrm{ng} / \mathrm{ml} \mathrm{EGF,} \mathrm{50ng/ml} \mathrm{Noggin,} \mathrm{and} \mathrm{100ng/ml} \mathrm{R-Spondin} \mathrm{in} \mathrm{Advanced} \mathrm{DMEM/f12).}$ Sorted cells were plated on 2.5\% Matrigel (Corning \#356231) coated 12mm coverslips at a concentration of $\sim 5-10 \mathrm{k}$ enteroendocrine cells per coverslip. Nodose neurons were dissociated from C57 BL/6J wild-type mice as described in the calcium imaging section. Neurons in media were plated evenly on up to 8 coverslips with enteroendocrine cells. Patch-clamp electrophysiology was performed 2-3 days after plating.

Patch-clamp electrophysiology. Enteroendocrine cells and nodose neurons were co-cultured as described in the co-culture section. Co-culture coverslips were placed in the recording chamber filled with extracellular solution containing (in $\mathrm{mM}$ ): $140 \mathrm{NaCl}, 5 \mathrm{KCl}, 2 \mathrm{CaCl} 2,2 \mathrm{MgCl} 2,10$ HEPES (pH 7.4, 300-305 mOsm). CckCRE_tdTomato cells were identified by red fluorescence and neurons by their morphology and lack of fluorescence. Recordings were made using borosilicate glass pipettes pulled to $\sim 3.5 \mathrm{M} \Omega$ resistance. For voltage-clamp recordings, intracellular solution contained (in $\mathrm{mM}$ ): $140 \mathrm{CsF}, 10 \mathrm{NaCl}, 0.1 \mathrm{CaCl} 2,2 \mathrm{MgCl} 2,1.1 \mathrm{EGTA}, 10$ HEPES, 10 sucrose ( $\mathrm{pH}$ 7.25, 290 - $295 \mathrm{mOsmol}$ ). Neurons were held at $-50 \mathrm{mV}$ for 2 min after patching in voltage-clamp mode to stabilize cells. Membrane time constant, cell capacitance, and voltage threshold were determined using $200 \mathrm{~ms}$ steps from $-50 \mathrm{mV}$ to $+20 \mathrm{mV}$ in $10 \mathrm{mV}$ increments. Stimuli were delivered using the SmartSquirt Microperfusion system (Automate Scientific, Inc.). Then, the SmartSquirt nozzle was brought to within $100 \mu \mathrm{m}$ of the paired enteroendocrine cell. While extracellular solution was perfusing through the chamber ( $\sim 2 \mathrm{ml} / \mathrm{min}$ ), either $20 \mathrm{mM}$ glucose or $2 \mathrm{mM}$ sucralose was puffed onto the cell and its axonal arbor via the SmartSquirt needle. Baseline neuronal activity was recorded in voltage-clamp for 2 min before exposure to either stimulus in alternating order for 30-60 sec, followed by a wash with extracellular solution. After exposure to stimuli, neurons were re-tested with voltage steps as described above to confirm the health of the cell. 
Data Acquisition: Recordings were carried out at room temperature using a MultiClamp 700B amplifier (Axon Instruments), digitized using a Digidata 1550A (Axon Instruments) interface, andvisualized in pClamp software (Axon Instruments). Data were filtered at $1 \mathrm{kHz}$ and sampled at $10 \mathrm{kHz}$.

Data Analysis: Cell capacitance was calculated as $\mathrm{Cm}=\left(\tau * \mathrm{I}_{0}\right) / \Delta \mathrm{E}$, where $\tau=$ time constant of the decaying current transient, $\Delta \mathrm{E}=$ voltage step, and $\mathrm{I}_{0}=$ current transient relative to pre-pulse potential (Platzer, 2016 \#123). To account for cell variability and health, max current was normalized to the cell capacitance. Data are presented as the mean \pm S.E.M. in log scale. Significance was determined using a two-tailed Student's t test with $\alpha=0.05$.

Single cell RNA sequencing. Left $(n=6)$ and right $(n=5)$ nodose ganglia adult C57 BL/6J wildtype euthanized mice were dissected as described in the calcium imaging section and separated into two distinct tubes. Dissections were completed in tandem by three lab members, and all nodose were dissected within 30 minutes at which point $55 \mu \mathrm{g}$ of Liberase (Roche) was added to each tube. Ganglia were dissociated into single cells as described in the co-culture section. The dissociated solution was then carefully laid upon a density gradient of $500 \mu \mathrm{L} 12 \%$ and $500 \mu \mathrm{L}$ $28 \%$ Percoll (Sigma) and centrifuged for 10 minutes at 2,900 x g at room temperature. Once centrifugation was complete, the top $700 \mu \mathrm{L}$ was removed, and $700 \mu \mathrm{L}$ of fresh dissociation solution was added. Cells were then centrifuged for 15 mins at 2,900 x g, and the final pellet was resuspended in $500 \mu \mathrm{L}$ of PBS $+0.04 \%$ BSA and passed to the Duke University Human Vaccine Institute Sequencing Core for further processing. Capturing of single cells was performed using Chromium Single-cell 3' v2. cDNA synthesis with PCR and library preparation were done according to the manufacturer's guidelines. Libraries were sequenced on an Illumina NextSeq 500. The Cell Ranger pipeline version 2.1.1 was used with the mm10 mouse reference genome version 2.1.0 to convert base calls to fastq, align, map, and count genes.

Analysis of nodose single cell sequencing data. R-package Seurat version 3.1.0 was used for the analysis. ${ }^{49}$ We integrated our dataset with the published atlas for the nodose ganglia as a reference. ${ }^{50}$ A total of 5,847 cells were sequenced with a mean of 137,352 reads and 2,817 genes detected per cell. Cells were filtered for gene content (fewer than 1000 or greater than 6000 genes detected were removed) and mitochondrial content (greater than 10\%), leading to the removal of 340 cells prior to merging the left and right nodose data sets. ${ }^{49}$ Normalization, feature selection, scaling, and linear dimensional reduction were then performed using default parameters in Seurat. Transfer "anchors" between our data set and the reference published set were determined using the algorithm implemented in Seurat, and we classified our cells into the 24 clusters previously identified. Cluster identities were confirmed with expression levels of cluster markers, and gene expression levels across clusters was visualized using Uniform Manifold Approximation and Projection (UMAP). For glutamate and ATP receptor genes, we determined a composite gene expression of ionotropic (Gria, Grik, Grin; P2rx) and metabotropic (Grm; P2ry) family receptor genes by summing counts for the respective genes in each cell.

Flexible gut "Illumenator" implant fabrication. Waveguide fabrication. The step-index core/cladding flexible polymer waveguide was fabricated using the Thermal Drawing Process (TDP) starting from a macroscopic polymer preform (template). ${ }^{32,33,51}$ The preform was 
assembled by inserting a polycarbonate (PC) rod (1/8" diameter, McMaster-Carr) into a polymethyl methacrylate (PMMA) tube (1/4" outer diameter and 1/8" inner diameter; US Plastics Corp.) and then consolidating the rod-in-tube assembly at $170^{\circ} \mathrm{C}$ in a vacuum oven. The resulting preform was drawn into meters long fiber in a custom-built fiber drawing tower at a temperature of $270^{\circ} \mathrm{C}$. The lateral dimensions of the preform were reduced by 30 times to produce a microscopic (220-230 $\mu \mathrm{m}$ diameter) PC/PMMA core/cladding optical waveguide.

Physical characterization of flexible polymer Waveguide. Optical transmission loss of the fibers was quantified by coupling the fibers to a diode-pumped solid state (DPSS) laser (Laserglow, 50$\mathrm{mW}$ maximum output, wavelength $\lambda=473 \mathrm{~nm}$ ) via ferrules and the light output was measured by a photodetector (S121C, 400-1,100 nm, $500 \mathrm{~mW}$, Thorlabs) attached to power meter (PM100D, Thorlabs). Optical transmission was quantified for a range of fiber lengths $(1-10 \mathrm{~cm})$, bending angles $\left(0^{\circ}, 90^{\circ}, 180^{\circ}\right.$ and $\left.270^{\circ}\right)$, and radii of curvature $(0.5,1,2.5,5,7.5,10,12.5$ and $15 \mathrm{~mm})$.

Gut implant fabrication. To optically couple as-drawn fibers to a light source, $9-10 \mathrm{~cm}$ long fibers were inserted into a $10.5 \mathrm{~mm}$-long, 2.5 -mm-diameter, $231 \mu \mathrm{m}$ bore size ceramic ferrule (Thorlabs) and affixed with optical epoxy (Thorlabs). The ferrule edge was then polished using a Thorlabs fiber polishing kit. Fiber was then threaded through $\sim 7.5 \mathrm{~cm}$ of micro-renathane tubing (BrainTree Scientific) to provide structural stability for tunneling. The proximal $\sim 6.75 \mathrm{~cm}$ of the tubing closest to the ferrule was opacified with liquid electrical tape (Starbrite) to reduce nonspecific activation of Cck expressing cells in the skin (Fig. 6a). The final length of the device was $\sim 9.25 \mathrm{~cm}$ including the ferrule; $\sim 1.5 \mathrm{~cm}$ of the device could be illuminated and $\sim 0.75 \mathrm{~cm}$ of fiber extended beyond the tubing. The average power recorded from the device tip was measured using a photodetector (S140C, 250-1100 nm, $500 \mathrm{~mW}$; Thorlabs) attached to a power meter (PM100D, Thorlabs). Average power output at the end of the PC/PMMA fiber with a 5V, 40Hz, $532 \mathrm{~nm}$ laser input was $13.3 \pm 0.107 \mathrm{~mW} / \mathrm{cm}^{2}$ before implantation and $10.2 \pm 1.43 \mathrm{~mW} / \mathrm{cm}^{2} 4-8$ weeks after implantation following completion of behavioral studies $(\mathrm{n}=11)$.

Gut fiberoptic implantation surgery. Adult CckCRE_Halo-YFP mice and adult CckCRE_ChR2-tdTom were single-housed and acclimated to behavioral cages (TSE PhenoMaster) one week prior to surgery. Mice were anesthetized with isoflurane $(1-3 \%$ in oxygen). A $2 \mathrm{~cm}$ incision was made from the xiphoid process diagonally to left-mid clavicular line. The peritoneal cavity was accessed, and the stomach extra-corporealized for implantation. A purse string suture was made in the gastric antrum, avoiding blood vessels. A small incision was made in the stomach within the suture, and a gavage needle was used to dilate the pylorus. The distal end of the device was threaded into the proximal duodenum so that the illuminated region of the device was in the proximal small intestine (Fig. 4e). The purse string stitch was tied to secure the device in the intestine. The opacified portion of the device was tunneled to the base of the skull. The peritoneum and overlying skin were sutured. The device exited the tunnel at the base of the skull and was skull mounted; skull mounting was required to maximize longevity of the implant. For maximal adhesion, the skull was etched with a razor blade and a thin layer of Metabond cement (Clear L-powder S399 + catalyst; Metabond) was applied. Then, the Metabond layer was etched and the device attached using standard dental cement (Stoelting \#51458). Mice recovered for at least 5 days or until normal feeding behavior and activity returned. 
Duodenal catheter surgery. Adult C57BL/6J wild-type mice were surgically implanted with catheters into the duodenum with a similar procedure as previously described., ${ }^{4,52}$ Mice were anesthetized with isoflurane (1-3\% in oxygen). A $2 \mathrm{~cm}$ incision was made from the xiphoid process diagonally to the left-mid clavicular line. The peritoneal cavity was accessed, and the stomach extra-corporealized for catheter implantation. Micro-renathane tubing (BrainTree Scientific) with one silicone ball (Home Depot) at implantation end was inserted into a small incision made in the stomach within a purse string suture. The distal end of the catheter was threaded into the proximal duodenum, and the silicone ball was sutured inside the stomach to keep the catheter in place. The other end of the catheter was tunneled to the back and directed out in the small intrascapular incision. This end was secured in place with surgical mesh. The proximal end of the catheter was sealed with a metal cap. Mice were then singly housed and recovered for at least 5 days until normal feeding behavior and activity returned.

Phenotyping equipment. All optogenetic behavior experiments were performed in a PI managed husbandry system. Animals were housed in a custom-built PhenoMaster behavioral phenotyping system (TSE Systems Inc. Chesterfield, MO). The PhenoMaster was programmed (software version 6.6.9) to automatically maintain a light cycle (0700 lights on; 1900 lights off), temperature control $\left(22^{\circ} \mathrm{C}\right)$, and humidity control $(40 \%)$. The PhenoMaster holds 12 clear cages in which animals were singly housed. Cages were industrially washed and bedding (ALPHA-dri) replaced weekly. Animals were provided with standard mouse chow (Purina 5001) and reverse osmosis water ad libitum unless fasted for a choice assay. All cages also housed an enrichment device, which also served to weigh the animals. Food hopper, water bottle, and weigh container were attached to weight sensors (TSE). Food intake, water intake, and weight were automatically measured every 5 seconds to the nearest 0.01 g. For drinking measurements, a 10 second smoothing interval with a maximum raw analog-to-digital conversion counts difference of 40,000 was permitted. For weight measurements, a 15 -second smoothing interval with a $15 \mathrm{~g}$ threshold and a maximum raw analog-to-digital conversion counts difference of 1,000,000 was permitted. Intake was measured every 5 seconds and binned every minute for analyses unless otherwise indicated. Animal activity was determined by beams crossed in the $\mathrm{x}$ and y planes and was collected with a $100 \mathrm{~Hz}$ scan rate. For optogenetic stimulation experiments, custom PhenoMaster software drove scheduled TTL pulses which triggered laser on/off. For optogenetic experiments, TTL signals were set to be triggered every 3 minutes. Each cycle included oneminute on with $40 \mathrm{~Hz}, 5 \mathrm{~V}$ pulse at $20 \%$ duty cycle, and two-minutes off. Each experimental session with laser stimulation began with 1-minute laser on. Following experiments, raw data was downloaded from the Phenomaster software and analyzed using MATLAB software (Mathworks). Unless otherwise indicated, all activity, food intake, and water intake measurements were binned in 1-minute intervals for analysis. Data was corrected for minor fluctuations by only permitting a monotonically increasing function for both food and water intake: values that represented positive food intake were replaced by the most recent value.

Plexiglass cage manufacturing. The choice assay paired with intraluminal drug delivery occurred in in-house manufactured clear plexigass cages. Clear plexigass (Home Depot Model \# acr0802448; $0.08 \times 24 \times 48$ inch) was manufactured into cages with an $8 \times 8$ inch base and four 10 inch tall walls, secured with clear silicone (Loctite waterproof sealant). The walls were snapcut by hand in our laboratory or in the Duke Engineering machine shop. The top of the cage was 
open. To allow mice to move around the cage freely, a custom swivel arm (TSE), which introduced the tubing to attach to each catheter, was secured on one wall with a custom 3-D printed device. This device was essentially a tube which snuggly fit around the metal swivel arm to hold it upright and was super glued to one side of the cage.

Choice assay. Mice were given free access to $300 \mathrm{mM}$ sucrose and $15 \mathrm{mM}$ sucralose for 24 hours in the home cage to control for neophobia. During 24-hour access, mice had ad libitum access to food and water, though water intake was negligible; implanted mice were not connected to patch cables. For each subsequent choice assay, at the start of the dark cycle (1900), mice were placed in a cage with fresh bedding and restricted of food and water either in the Phenomaster or plexiglass cages. One hour after onset of dark cycle (2000), 300mM sucrose and $15 \mathrm{mM}$ sucralose became available for free consumption for 1 hour. Concentrations were selected based on prior studies showing iso-sweetness. ${ }^{53,54}$ The side of the sucrose and sucralose solutions was swapped each test to control for side preferences. In order to advance to optogenetic or pharmacologic inhibition, mice were required to display a stable preference for sucrose, defined as $>66 \%$ sucrose preference in two consecutive tests, not varying by more than $15 \%$ across both tests. For five mice who did not display a clear preference by the seventh test, or displayed a clear side preference by the third test, were re-exposed for 24 hours as above. Average number of test days to advance to inhibition was 5.24. Following each test session, mice were disconnected when appropriate (optogenetic and intraduodenal infusion tests) and given ad libitum access to food and water. The start of all test sessions was separated by at least 48 hours.

Optogenetic inhibition. Implanted CckCRE_Halo-YFP mice (final $\mathrm{n}=8, \mathrm{n}=5$ male $/ 3$ female) and their wild-type littermates (final $n=5, n=3$ male/ 2 female) underwent baseline choice assays as described in choice assay section. Testing occurred in our TSE PhenoMaster apparatus. During all baseline and experimental assays, mice were connected to the laser using a custom swivel arm (TSE) coupled to a rotary joint patch cable (ThorLabs, \#RJPFF2) for free movement at the time of dark onset for consistency and acclimation. Once a stable preference was established, each mouse underwent two experimental conditions: $532 \mathrm{~nm}$ (silencing) laser and 473nm (control) light, followed by a repeated baseline. Order of laser wavelength was counterbalanced to control for order effect. During photo-stimulation conditions, the Phenomaster delivered a TTL pulse for laser stimulation: 1 minute on $(5 \mathrm{~V}, 40 \mathrm{~Hz}, 20 \%$ duty cycle) and 2 minutes off for the full hour. The following analyses were assessed: minute-tominute sucrose and sucralose consumption, preference for sucrose relative to the total amount of volume consumed, motor activity, and food/chow intake over 24 hours following assay. Fiberoptic placement and power output was confirmed at the end of the study. Only mice who completed all four tests and whose device had appropriate power/placement were included in analysis. Four mice were excluded for the following reasons: 1 mouse for low power, 3 mice due to a strong side preference.

Pharmacologic inhibition with intraperitoneal injections. C57BL/6J wild-type mice (for CCK-A inhibition, final $\mathrm{n}=4, \mathrm{n}=3$ male/ 1 female); for IP glutamate receptor inhibition, final $\mathrm{n}=4, \mathrm{n}=$ 2 male/ 2 female) underwent baseline choice assays as described in choice assay section. During acclimation period, wild type mice received intraperitoneal injections of PBS to acclimate them to the procedure. Once a stable sucrose preference was established, each mouse underwent two experimental conditions: drug and vehicle. Order of injection was counterbalanced. Separate 
cohorts of wild type mice were used to test the effect of the CCK inhibitor devazepide (Bachem) and the glutamate receptor inhibitor cocktail KA/AP3 (Sigma). ${ }^{42,43}$ Testing occurred in our TSE PhenoMaster apparatus as described in the optogenetics section or plexiglass cages. For experiments in plexiglass cages, solution intake was measured to the nearest $0.1 \mathrm{~mL}$ manually every 5 minutes from $5 \mathrm{~mL}$ serological pipettes fashioned as sippers. For CCK-A inhibition, devazepide was delivered $2 \mathrm{mg} / \mathrm{kg}(10 \mu \mathrm{L} / \mathrm{g})$ dissolved in 5\% DMSO in PBS. Devazepide or vehicle (5\% DMSO in PBS) was injected intraperitoneally 30 minutes prior to choice assay based on prior reports. ${ }^{17}$ For glutamate receptor inhibition, stock solutions of kynurenic acid and AP-3 were made in $1 \mathrm{M} \mathrm{NaOH}$ and experimental concentration were diluted in PBS, $\mathrm{pH} 7.4$. $\mathrm{KA} / \mathrm{AP}-3$ were delivered at $150 \mu \mathrm{g} / \mathrm{kg}$ and $1 \mathrm{mg} / \mathrm{kg}$, respectively, and delivered $10 \mu \mathrm{L} / \mathrm{g}$. KA/AP3 cocktail or vehicle (equivalent volume $1 \mathrm{M} \mathrm{NaOH}$ in $\mathrm{PBS}, \mathrm{pH} 7.4$ ) was delivered intraperitoneally immediately before testing. Two mice were excluded from further study due to a strong side preference.

Pharmacologic inhibition with intraluminal injections. C57BL/6J wild-type mice (final $\mathrm{n}=4, \mathrm{n}$ $=3$ male/ 1 female) were implanted as described in the duodenal catheter surgery section and underwent baseline choice assays as described in choice assay section. Catheters were flushed with $0.05 \mathrm{~mL}$ PBS daily and immediately before the one-hour food and water deprivation (dark onset). Testing occurred in our plexiglass cages with syringes (solution intake measured manually every 5 minutes). Immediately prior to the one-hour test session, mice were attached to micro-renathane tubing which delivered drug, vehicle, or control solutions via an infusion pump (Fusion 200, Chemyx). The infusion pump was started, which delivered $0.4 \mathrm{~mL}$ of the appropriate solution over the one-hour test session (flow rate was $0.0066 \mathrm{~mL} / \mathrm{minute}$ ). PBS solutions were delivered intra-intestinally during baseline tests. For glutamate receptor inhibition, KA/AP3 cocktail (15 ng KA and $0.1 \mu \mathrm{g}$ AP-3) or vehicle (1M NaOH in PBS, pH 7.4) was delivered intra-intestinally in $0.4 \mathrm{~mL}$. Catheter placement was confirmed at the end of the study by visual inspection of the small intestine following the infusion of a dye solution through the catheter. One mouse was sacrificed before the final baseline test out of concern for stability of the implant. However, the catheter was confirmed to be in the duodenum, and its data were included. One mouse was excluded from further study due to a strong side preference.

One-bottle assay. CckCRE_ChR2 mice (final $n=4, n=2$ male/2 female) were acclimated to the PhenoMaster and implanted with flexible fiberoptic implants as described above (section: Gut fiberoptic implantation surgery). Implanted mice were given free access to sucrose $[300 \mathrm{mM}]$ or sucralose $[15 \mathrm{mM}]$ separately for 24 hours in the home cage to control for neophobia; exposures were separated by at least 48 hours. During 24-hour access, mice had ad libitum access to food and water, though water intake was negligible; implanted mice were not connected to patch cables during exposure. For each one-bottle assay, 5 minutes before the start of the dark cycle, access to food and water was closed and mice were attached to the rotary joint patch cable (ThorLabs, \#RJPFF2) in the Phenomaster; mice remained in the home cage. At the start of the dark cycle, $300 \mathrm{mM}$ sucrose OR $15 \mathrm{mM}$ sucralose became available for free consumption for 1 hour. The side of the solution was the same for all studies. Following each test session, mice were disconnected and given ad libitum access to food and water. The start of all test sessions was separated by at least 48 hours. 
Each mouse underwent two baseline conditions (sucrose [300mM] no laser, sucralose [15mM] no laser) followed by four experimental conditions: sucrose $+473 \mathrm{~nm}$ (activating), sucrose + $532 \mathrm{~nm}$ (control), sucralose $+473 \mathrm{~nm}$, and sucralose $+532 \mathrm{~nm}$. Order of experimental conditions were counterbalanced to control for order effect. During photo-stimulation conditions, the Phenomaster delivered a TTL pulse for laser stimulation based on intake as follows: for every $0.01 \mathrm{~g}$ of liquid consumed, the mice received 5 seconds of laser stimulation $(5 \mathrm{~V}, 40 \mathrm{~Hz}, 20 \%$ duty cycle). Fiberoptic placement and power output was confirmed at the end of the study. Only mice who completed all six tests and whose device had appropriate power/placement were included in analysis. One mouse was excluded from analysis for low device power at sacrifice.

Statistics and reproducibility. We performed statistical analyses using JMP Pro Software (Version 14, SAS), unless otherwise indicated. For comparison of means, ANOVA was used and post-hoc testing was performed when applicable. For vagal nerve recordings, we performed Tukey HSD post-hoc testing. For behavior studies, we used a repeated measure ANOVA to account for each subject and followed with post-hoc paired student's t-tests. For other studies, comments on statistical tests performed is included throughout methods and in figure legends. All error bars and shaded regions represent standard error of the mean (SEM) unless otherwise indicated. Sample size was not pre-determined using power analyses. All behavioral studies were counterbalanced across gender and sex to control for variables including position in cage, order effect, and handedness. Experimenters were not blinded to treatment condition, genotype, or outcome.

\section{References}

1. Miller, N. E. \& Kessen, M. L. Reward effects of food via stomach fistula compared with those of food via mouth. J. Comp. Physiol. Psychol. 45, 555-564 (1952).

2. Sclafani, A. Post-ingestive positive controls of ingestive behavior. Appetite 36, 79-83 (2001).

3. de Araujo, I. E. et al. Food Reward in the Absence of Taste Receptor Signaling. Neuron (2008) doi:10.1016/j.neuron.2008.01.032.

4. Han, W. et al. Striatal Dopamine Links Gastrointestinal Rerouting to Altered Sweet Appetite. Cell Metab. 23, 103-112 (2016).

5. Bohórquez, D. V. et al. Neuroepithelial circuit formed by innervation of sensory enteroendocrine cells. J. Clin. Invest. 125, 782-786 (2015).

6. Williams, E. K. K. et al. Sensory Neurons that Detect Stretch and Nutrients in the Digestive System. Cell (2016) doi:10.1016/j.cell.2016.05.011.

7. Su, Z., Alhadeff, A. L. \& Betley, J. N. Nutritive, Post-ingestive Signals Are the Primary Regulators of AgRP Neuron Activity. Cell Rep. (2017) doi:10.1016/j.celrep.2017.11.036.

8. Beutler, L. R. et al. Dynamics of Gut-Brain Communication Underlying Hunger. Neuron (2017) doi:10.1016/j.neuron.2017.09.043.

9. Bohórquez, D. V. et al. Neuroepithelial circuit formed by innervation of sensory enteroendocrine cells. J. Clin. Invest. 125, (2015).

10. Kaelberer, M. M. et al. A gut-brain neural circuit for nutrient sensory transduction. Science (80-. ). (2018) doi:10.1126/science.aat5236.

11. Han, W. et al. A Neural Circuit for Gut-Induced Reward. Cell 175, 665-678.e23 (2018).

12. Damak, S. Detection of Sweet and Umami Taste in the Absence of Taste Receptor T1r3. 
Science (80-. ). 301, 850-853 (2003).

13. Domingos, A. I. et al. Leptin regulates the reward value of nutrient. Nat. Neurosci. 14, 1562-1568 (2011).

14. Sclafani, A. \& Ackroff, K. Operant licking for intragastric sugar infusions: Differential reinforcing actions of glucose, sucrose and fructose in mice. Physiol. Behav. 153, 115-124 (2016).

15. Booth, D. A. Satiety and behavioral caloric compensation following intragastric glucose loads in the rat. J. Comp. Physiol. Psychol. 78, 412-432 (1972).

16. Dus, M., Min, S. H., Keene, A. C., Lee, G. Y. \& Suh, G. S. B. Taste-independent detection of the caloric content of sugar in Drosophila. Proc. Natl. Acad. Sci. U. S. A. (2011) doi:10.1073/pnas.1017096108.

17. Pérez, C., Lucas, F. \& Sclafani, A. Devazepide, a CCK(A) antagonist, attenuates the satiating but not the preference conditioning effects of intestinal carbohydrate infusions in rats. Pharmacol. Biochem. Behav. 59, 451-457 (1998).

18. Mei, N. Vagal glucoreceptors in the small intestine of the cat. J. Physiol. (1978) doi:10.1113/jphysiol.1978.sp012477.

19. Sclafani, A. \& Ackroff, K. Operant licking for intragastric sugar infusions: Differential reinforcing actions of glucose, sucrose and fructose in mice. Physiol. Behav. 153, 115-124 (2016).

20. Crane, R. K. Intestinal Absorption of Sugars. Physiol. Rev. 40, 789-825 (1960).

21. Reimann, F. et al. Glucose Sensing in L Cells: A Primary Cell Study. Cell Metab. 8, 532539 (2008).

22. Sclafani, A., Koepsell, H. \& Ackroff, K. SGLT1 sugar Transporter/Sensor is required for post-oral glucose appetition. Am. J. Physiol. - Regul. Integr. Comp. Physiol. (2016) doi:10.1152/ajpregu.00432.2015.

23. Dyer, J., Salmon, K. S. H., Zibrik, L. \& Shirazi-Beechey, S. P. Expression of sweet taste receptors of the T1R family in the intestinal tract and enteroendocrine cells. Biochem. Soc. Trans. 33, 302-305 (2005).

24. Ninomiya, Y.\& Imoto, T. Gurmarin inhibition of sweet taste responses in mice. Am. J. Physiol. - Regul. Integr. Comp. Physiol. 268, (1995).

25. Ehrenkranz, J. R. L., Lewis, N. G., Kahn, C. R. \& Roth, J. Phlorizin: A review. Diabetes. Metab. Res. Rev. 21, 31-38 (2005).

26. Bellono, N. W. et al. Enterochromaffin Cells Are Gut Chemosensors that Couple to Sensory Neural Pathways. Cell 170, 185-198.e16 (2017).

27. Lu, V. B. et al. Adenosine triphosphate is co-secreted with glucagon-like peptide-1 to modulate intestinal enterocytes and afferent neurons. Nat. Commun. 10, (2019).

28. Daly, K. et al. Sensing of amino acids by the gut-expressed taste receptor T1R1-T1R3 stimulates CCK secretion. Am. J. Physiol. - Gastrointest. Liver Physiol. (2013) doi:10.1152/ajpgi.00074.2012.

29. Sato, T. et al. Single Lgr5 stem cells build crypt-villus structures in vitro without a mesenchymal niche. Nature 459, 262-265 (2009).

30. Fujii, M., Matano, M., Nanki, K. \& Sato, T. Efficient genetic engineering of human intestinal organoids using electroporation. Nat. Protoc. 10, 1474-1485 (2015).

31. Finger, T. E. ATP Signaling Is Crucial for Communication from Taste Buds to Gustatory Nerves. Science (80-. ). 310, 1495-1499 (2005).

32. Canales, A. et al. Multifunctional fibers for simultaneous optical, electrical and chemical 
interrogation of neural circuits in vivo. Nat. Biotechnol. 33, 277-284 (2015).

33. Park, S. et al. One-step optogenetics with multifunctional flexible polymer fibers. Nat. Neurosci. 20, 612-619 (2017).

34. Sapolsky, R. M. Behave : the biology of humans at our best and worst. (Penguin Press, 2017).

35. Wang, Y. et al. Amino acids stimulate cholecystokinin release through the Ca $2+$-sensing receptor . Am. J. Physiol. Liver Physiol. 300, G528-G537 (2010).

36. Sato, T. et al. Single Lgr5 stem cells build crypt-villus structures in vitro without a mesenchymal niche. Nature 459, 262-5 (2009).

37. Saxena, K. et al. Human Intestinal Enteroids : a New Model To Study Human. J. Virol. 90, 43-56 (2016).

38. Nawrot, M., Aertsen, A. \& Rotter, S. Single-trial estimation of neuronal firing rates: From single-neuron spike trains to population activity. J. Neurosci. Methods 94, 81-92 (1999).

39. Sigoillot, M., Brockhoff, A. \& Meyerhof, W. Sweet-taste-suppressing compounds : current knowledge and perspectives of application. 619-630 (2012) doi:10.1007/s00253012-4387-3.

40. Ohkuri, T. et al. Multiple sweet receptors and transduction pathways revealed in knockout mice by temperature dependence and gurmarin sensitivity. Am J Physiol Regul Integr Comp Physiol 296, R960-R971 (2009).

41. Beutler, L. R. et al. Dynamics of Gut-Brain Communication Underlying Hunger. Neuron 96, 461-475.e5 (2017).

42. Bäckström, P. \& Hyytiä, P. Ionotropic Glutamate Receptor Antagonists Modulate CueInduced Reinstatement of Ethanol-Seeking Behavior. Alcohol. Clin. Exp. Res. 28, 558565 (2004).

43. Shang, Y. et al. Fragile X mental retardation protein is required for chemically-induced long-term potentiation of the hippocampus in adult mice. J. Neurochem. 111, 635-646 (2009).

44. Rong, W., Burnstock, G. \& Spyer, K. M. P2X purinoceptor-mediated excitation of trigeminal lingual nerve terminals in an in vitro intra-arterially perfused rat tongue preparation. J. Physiol. 524, 891-902 (2000).

45. Ribeiro, T. et al. Blockade of ATP P2X7 receptor enhances ischiatic nerve regeneration in mice following a crush injury. Brain Res. 1669, 69-78 (2017).

46. Borsani, E. et al. PPADS, a purinergic antagonist reduces Fos expression at spinal cord level in a mouse model of mononeuropathy. Brain Res. 1199, 74-81 (2008).

47. Ståhlberg, A., Rusnakova, V., Forootan, A., Anderova, M. \& Kubista, M. RT-qPCR workflow for single-cell data analysis. Methods 59, 80-88 (2013).

48. Kaelberer, M. M. \& Jordt, S. E. A method to target and isolate airway-innervating sensory neurons in mice. J. Vis. Exp. 2016, 1-7 (2016).

49. Stuart, T. et al. Comprehensive Integration of Single-Cell Data. Cell 177, 1888-1902.e21 (2019).

50. Kupari, J., Häring, M., Agirre, E., Castelo-Branco, G. \& Ernfors, P. An Atlas of Vagal Sensory Neurons and Their Molecular Specialization. Cell Rep. 27, 2508-2523.e4 (2019).

51. Lu, C. et al. Flexible and stretchable nanowire-coated fibers for optoelectronic probing of spinal cord circuits. $S c i$. Adv. 3, 1-8 (2017).

52. Su, Z., Alhadeff, A. L. \& Betley, J. N. Nutritive, Post-ingestive Signals Are the Primary Regulators of AgRP Neuron Activity. Cell Rep. 21, 2724-2736 (2017). 
bioRxiv preprint doi: https://doi.org/10.1101/2020.03.06.981365; this version posted March 8, 2020. The copyright holder for this preprint (which was not certified by peer review) is the author/funder. All rights reserved. No reuse allowed without permission.

53. Sclafani, A. \& Ackroff, K. Flavor preferences conditioned by nutritive and non-nutritive sweeteners in mice. Physiol. Behav. 173, 188-199 (2017).

54. Domingos, A. I. et al. Leptin regulates the reward value of nutrient. Nat. Neurosci. 14, 1562-1568 (2011). 